\title{
Happiness Without a Financial Safety Net: Low Income Predicts Emotional Volatility*
}

\author{
Sergio Pirla ${ }^{\dagger} \quad$ Jordi Quoidbach ${ }^{\ddagger}$
}

December 9, 2021

\begin{abstract}
Decades of research suggest that money buys very little happiness. However, previous studies have relied on static measures assessing people's well-being once or on average. We examine the "reel" of people's emotional lives through over 1 million reports from 23,000 individuals whose happiness was tracked in real-time using a smartphone app. Results show that lower income is associated with increased happiness volatility - a relationship that replicates across multiple operationalizations of volatility, statistical models, and a sample of individuals from six developing countries $(\mathrm{N}>25,000)$. An unsupervised anomaly detection algorithm further revealed that the greatest gap is between how frequent and intense the rich and the poor experience emotional downs, not ups. The happiness gap between the highest and lowest earners during episodes of intense unhappiness was 1.5 to 3 times the size of the gap in average happiness between these two groups. Finally, exploiting the exogeneity of monthly payments, we find that low-income people experience more moments and periods of anomalous happiness the last few days of the month, suggesting a causal relationship between income and happiness volatility.
\end{abstract}

${ }^{*}$ Jordi Quoidbach thanks the Ministerio de Economia, Industria y Competitividad, Gobierno de España (Grant No. RYC-2016-21020) for financial support. To access the code and data that support the findings of this paper, use the following link: Link.

${ }^{\dagger}$ Universitat Pompeu Fabra, Barcelona, Spain. Email: sergio.pirla@upf.edu

$\ddagger$ Universitat Ramon Llull, ESADE, Barcelona, Spain. 


\section{Introduction}

Global poverty is rising for the first time in over 20 years due to the triple threat of COVID19, conflict, and climate change (Lakner et al., 2021). How will this affect the well-being of the 120 million "new poor" around the world? If there's a silver lining, it's in the decades of scholarly research suggesting that money buys very little happiness (Aknin et al., 2009; Boyce et al., 2017; Frey and Stutzer, 2002; Kahneman et al., 2006). For example, the most recent meta-analyses suggest that income explains only $1 \%$ to $5 \%$ of how happy people feel overall (Jantsch and Veenhoven, 2019; Tan et al., 2020).

Yet, poverty has led to both individual and mass protests around the world. Have the hundreds of studies asking whether money buys happiness overlooked an important side of the question? One commonality shared by previous studies, whether they rely on global evaluative measures (e.g., "how happy do you feel in general?") or momentary measures of affect in situ (e.g., "how happy do you feel right now?"), is that they solely capture people's happiness once or on average. But a poor person reporting that they are only a percent less happy than a rich person overall doesn't mean their day-to-day emotional experiences are the same. When you're struggling to stay afloat, even regular events like paying your phone bill or rent can cause you to sink - not to mention drowning when catastrophes strike (Daly and Kelly, 2015; Morduch, 1994). The relationship between money and happiness may be less about general happiness than how much happiness fluctuates. And on an emotional rollercoaster, there could be moments of acute suffering or even extended periods of distress which could easily be missed when taking a snapshot of a person's emotional life.

We shouldn't overlook if the poor are afflicted by frequent emotional dips and crashes triggered by events that others cruise past. Hundreds of studies in psychology, psychiatry, and medicine show that emotional volatility is a key feature of bipolar, depressive, and anxiety disorders (aan het Rot et al., 2012; Anestis et al., 2010; Bowen et al., 2004; EbnerPriemer et al., 2007; Golier et al., 2001; Houben et al., 2015; Jones et al., 2005; Koval et al., 2013; Kuppens, 2015; Kuppens and Verduyn, 2017; McConville and Cooper, 1996; Pfaltz 
et al., 2010; Santangelo et al., 2014; Servaas et al., 2017; Snir et al., 2017; Thompson et al., 2012; Zeigler-Hill and Abraham, 2006) — all leading causes of disability worldwide and major contributors to the global burden of disease (Murray et al., 2012; Vos et al., 2016). Emotional volatility can also impose a severe tax on a person's physical health (Hardy and Segerstrom, 2017; Jenkins et al., 2018; Koval et al., 2013) - for a review, see Houben et al. (2015). For example, emotional volatility is related to increases in cardiac conditions (Chan et al., 2016). Moreover, relatively rare moments of severe emotional distress can foster behaviors that have far-reaching consequences, from overeating, substance abuse, and gambling (Ciccarelli et al., 2017; Hull et al., 1986; Masheb and Grilo, 2006) to self-harm, aggression, and violence (Berkowitz, 1989; Gratz, 2003).

A number of policy initiatives call for better measures of well-being as a means of enhancing policies that improve people's lives (OECD, 2011; UN, 2012). Here, we respond to these calls by addressing the limitations of static measures in a comprehensive study of emotional dynamics among people from various income brackets. First, we examine the relationship between income and happiness volatility in a sample of over 23,000 people whose happiness was tracked in real-time for several weeks using a smartphone app. We then corroborated our results by comparing happiness volatility in an independent data set of 25,634 people from six developing countries obtained from the World Health Organization Study on Global Aging and Adult Health (WHO SAGE). Going beyond traditional psychometric approaches, we used unsupervised anomaly detection and clustering algorithms to capture the subtle yet meaningful — ways income may shape our emotional lives. Finally, to provide suggestive evidence for a causal link between income and happiness dynamics, we examined how daily ups and downs change over the month as a function of income. 


\section{Methods}

\section{Participants and Experience Sampling.}

Participants volunteered for the study by downloading 58 seconds, a free iPhone and Android mobile app designed to measure users' well-being through short questionnaires presented at random times throughout the day. Participants could customize which days of the week, within what time windows, and how many times they wished to receive questionnaire requests (default $=4$ questionnaires a day; 7 days a week from 9:00 AM to 10:00 PM). The app then divided each participant's day into as many intervals as the number of requested questionnaires and chose a random time within each interval - setting a minimum of 1 hour between two questionnaires to avoid large artifactual autocorrelations. We ensured random sampling through a notification system that did not require an internet connection. The app generated notifications at new random times each day, independently for each participant.

Power analyses for affect dynamics time series (Pirla et al., 2021) revealed that ten happiness observations per participant would ensure reliable estimates across different operationalizations of happiness volatility (see hereafter). Therefore, our study focuses on 23,471 users who completed at least ten happiness reports. On average, these participants each provided 50.8 happiness observations, for a total of 1,191,912 observations. In line with previous research, we excluded from our primary analyses individuals whose income figure could not be reliably measured because they selected the lowest ("no income") and highest ("over 7500 euros") categories, respectively, leaving a final sample of 17,278 individuals, each providing an average 52.2 happiness observations (901,816 observations in total). Note that results on the entire sample of 23,471 people, treating income as an ordinal variable, yielded identical results (see SM Note 4). 


\section{Happiness.}

After accepting a questionnaire request, participants were presented with four to six questions drawn from an extensive battery of items - see Quoidbach et al. (2019). Here, our focal measure was a general happiness item ("How do you currently feel?"; answered on a slider from 0 "very unhappy" to 100 "very happy").

\section{Income and demographics.}

In addition to the repeated happiness item, participants were asked different demographic questions (once), including age, gender, country of residence, profession type, and monthly income after taxes (asked on a 13-point bracket scale, see Table S1 for detailed information on demographics and income distribution). The non-response rates were high for profession (44\%) and income (75\%). Because missingness of income data is typically related to key personal characteristics, including financial and health status, focusing only on completecase analysis can introduce important biases (Schenker et al., 2006). To handle missing data on profession and income, we performed an imputation by random forests using the MissRanger R-package (Mayer, 2019). Note that the direction and statistical significance of all the results we report do not change if we only focus on the subset of complete data or use an alternative hot deck imputation method (see SM Note 4).

\section{Measuring Happiness Volatility.}

There are five main operationalizations of affect volatility in the literature (see SM Note 2 for formal definitions). First, one can focus on overall affect variability using the withinparticipant standard deviation (iSD). While iSD is the most widely-used metric (Röcke et al., 2009), research demonstrates that variability in a construct can be dependent on mean levels of the same construct, especially when measurements are bounded within scales (Mestdagh et al., 2018). That is, a person with a mean happiness level of 10 (or a mean 
of 90) cannot display as much variability as somebody with a mean of 50 , since the scores of the latter individual are less constrained by the scale boundaries. To avoid confound with the mean, variability can be measured through a mean-adjusted version of the withinperson standard deviation (Relative iSD) that takes into account the maximum possible variance given an observed mean and scale endpoints (Mestdagh et al., 2018). Second, one can focus on affect instability from one moment to the next, using the Root Mean Square of Successive Differences (RMSSD), the Probability of Acute Change (PAC), and the TraegerKaiser Energy Operator (TKEO).

While each of these measures is designed to capture unique dynamical aspects of our emotional life, recent research shows considerable interdependencies between them (Dejonckheere et al., 2019). Therefore, for parsimony, we mainly report results for happiness volatility using within-person standard deviations, the most common and straightforward metric. Note that results were virtually identical for all other operationalizations of happiness volatility (see SM Note 3).

\section{Estimating the Income - Happiness Relationships.}

Several studies suggest that the relationship between money and happiness is not linear. Therefore, we examined how income is related to both averages and volatility in happiness through Generalized Additive Models (GAMs; Hastie and Tibshirani, 1987) using the mgcv package for R (Wood, 2003). These models allow fitting data with smooths, or splines, which are functions that can take on a wide variety of shapes. GAMs provide more flexibility than polynomial transformations in the GLM framework (Wood and Augustin, 2002) and limit the risk of false positives through a parsimonious automatic model selection process (Mckeown and Sneddon, 2014). For completeness, we also examined the income - happiness

relationships using two-lines tests, estimating separate regression lines for low and high values of income based on the Robin Hood algorithm (Simonsohn, 2018). The two-lines tests yielded identical conclusions to GAMs analyses (see SM Note 3). 


\section{Robustness and Specification Curves.}

We performed a specification curve analysis to ensure the robustness of our main finding that income is associated with happiness variability (Simonsohn et al., 2020). In this specification curve, we consider five different operationalizations of happiness volatility and three methods to deal with missing data (imputation by random forest, imputation by hot deck, and removing data from individuals with missing data). We considered income either as a continuous or categorical ordinal variable, with specifications including and excluding data from individuals who selected the highest income response ("more than 7500 euros/month) and imputing their income as 9000 euros per month. For specifications including income as an ordinal variable, we also examined the impact of including or excluding individuals who reported no income. Finally, we considered the effect of adding or removing demographic control variables from the models (Age, Gender, Country). To make the comparison of coefficients possible across specifications, we standardized our dependent variables. In total, we included 180 different specifications.

\section{Unsupervised Collective and Point Anomaly Detection.}

Classic models of affect dynamics assume that people's emotional lives can be summarized through a series of parametric measures (e.g., mean, variance, probability of acute change). However, these summary statistics often mask the complexity of human emotional life. To paint a detailed and complex picture of how income relates to everyday happiness, we used a Collective and Point Anomaly Detection method (Fisch et al., 2019). That is, we used a nonparametric penalty-based approach to identify happiness reports that are anomalous given an individual's happiness time series. To ensure reliable estimates, we focused our

analyses on a subsample of 5002 participants who provided a minimum of 50 happiness observations in our mobile app study (see SM Note 6 for details). 


\section{Results}

To set the stage for our primary analyses, we first examined the relationship between the logarithm of people's monthly income after taxes and their average happiness. We found a small association $(r=.075, p<.0001)$. Consistent with other studies (Jebb et al., 2018; Kahneman and Deaton, 2010; Killingsworth, 2021), Generalized Additive Models (GAMs; Hastie and Tibshirani, 1987), suggest that the relationship between income and average happiness was weaker at higher levels of income $(e d f=3.754, p<.0001$, deviance explained $=0.6 \%)$. On average, doubling one's salary from 1000 to 2000 euros per month was associated with a 0.08 SD increase in mean happiness (1.4 points out of 100 , Fig. 1; left panel). In contrast, doubling a person's salary from 3000 to 6000 euros per month was associated with a 0.07 SD increase in happiness (1.2 points). This pattern remained unchanged when controlling for age, gender, and country-specific fixed effects, as well as when using raw income in euros and categorical income ranks (see Specification Curve in SM Note 4).

Does money relate to happiness beyond how people feel on average? As shown in Fig. 1 (right panel), the logarithm of monthly income after taxes was negatively related to happiness volatility $(r=-.149, p<.0001)$, and GAM analyses suggest that the magnitude of this relationship decreased at higher levels of income $(e d f=2.933, p<.0001$, deviance explained $=$ $2.28 \%$ ), reaching a plateau at about 3,300 euros per month. On average, doubling one's salary from 1000 to 2000 euros per month was associated with a reduction in happiness volatility of 0.2 SD. In contrast, doubling a person's salary from 3000 to 6000 euros per month was virtually unrelated to happiness volatility changes (a decrease of $0.015 \mathrm{SD}$ ). Again, this pattern remained unchanged when controlling for age, gender, country-specific fixed effects, raw income, and categorical income ranks. The relationship also held for all major operationalizations of happiness volatility, including standard deviations, probability of acute changes (PAC), root mean successive square differences (RMSSD), and Teager-Kaiser energy opera-

tor (TKEO) - see Specification Curve in SM Note 4. Importantly, the relationship between income and happiness volatility remains significant when controlling for average happiness 
$(\beta=-.138, p<.0001 ; e d f=2.889, p<.0001)$ and when measuring happiness volatility using relative standard deviations $(r=-.119, p<.0001 ;$ edf $=2.776, p<.0001)-\mathrm{a}$ variability measure designed to account for the confounding of mean and standard deviation in bounded variables (Mestdagh et al., 2018). That is, the impact of income on happiness volatility cannot be explained by its effect on average happiness. Additional analyses show that the relationship between income and happiness volatility is not limited to our relatively wealthy European sample. We examined data from the World Health Organization SAGE study in which a sample of over 25,000 individuals from China, Ghana, India, Mexico, Russia, and South Africa reported their happiness an average of 4.8 times using a short Day Reconstruction survey and provided a measure of permanent income estimated from the household ownership of various country-specific durable goods (see SM Note 5). Regression analyses accounting for country-specific fixed effects revealed that permanent income predicted lower happiness volatility $(\beta=-.057, p<.0001)$ - a relationship robust to all major operationalizations of happiness volatility, and the inclusion of average happiness and different demographic controls (see SM Note 5).

Our findings show a robust association between financial hardship and people's propensity to experience volatile levels of happiness. But what does a volatile emotional life look like exactly? Because increased volatility was apparent across all major psychometric operationalizations and given the sizable statistical overlap between these metrics (Dejonckheere et al., 2019), it is difficult to fully appraise the shape of people's ups and downs. Therefore, going beyond classic affect dynamics measurements, we employed an unsupervised Collective and Point Anomaly (CAPA; Fisch et al., 2019) machine learning algorithm to identify and quantify how happiness changes as a function of income. Specifically, we first take a within-person approach and identify, for each participant, the presence of "anomalous" moments (i.e., observations) and periods (i.e., sequences of observations) in their happiness time series. We then take a between-person approach and examine whether income predicts people's propensity to experience anomalous happiness-related moments and periods, as well 
as the magnitude of these anomalies.

Fig. 2 provides a schematic representation of the CAPA results for prototypical respondents in the lowest and highest income group, respectively. Over $22 \%$ of participants experienced at least one anomalous happiness moment throughout the study. Most were instances in which individuals reported being a lot less happy than usual (88\%), and some were instances in which individuals reported being a lot happier (12\%). Income did not predict the frequency of extreme unhappiness moments $\left(\beta_{\log \text { income }}=.006, t=.42, p=.67\right)$, which happened on average every 330 happiness observations (i.e., approximately once every 3 months in our dataset). However, it was significantly related to their severity $\left(\beta_{\log \text { income }}=.12, t=3.36, p<.001\right)$. For example, participants in the lowest income group $(<1100$ euros/month) had extreme unhappy moments that were rated 7 points lower in happiness (an average of 23 vs. 30) than participants in the highest income group ( 6000 euros/month) - a difference over $50 \%$ larger than the gap in average happiness between the two groups (4.5 points). In contrast, income did not predict the magnitude of extreme
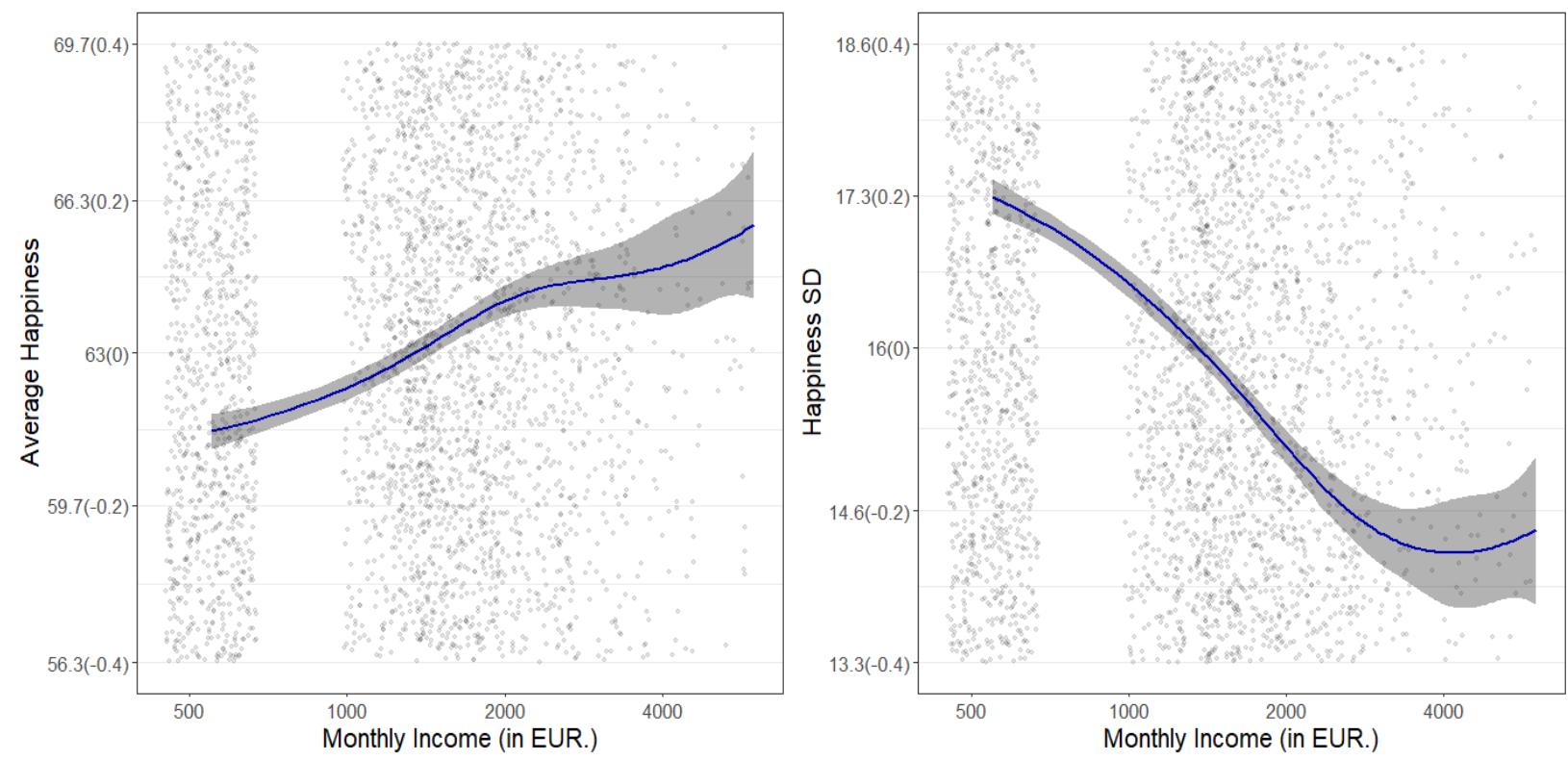

Figure 1: Average happiness (Left Panel) and happiness fluctuation (Right Panel) as a function of monthly income in the mobile application study (France, Belgium, and Switzerland). Shadow areas represent $95 \%$ confidence intervals. Standardized scores in parentheses. 
moments of happiness $\left(\beta_{\log \text { income }}=-.06, t=-.58, p=.56\right)$.

Anomalous periods were far more common than anomalous moments, with over $94 \%$ of people experiencing at least one sequence of happiness states that significantly differed from their typical sequences (e.g., a strange couple of days). K-means clustering (see SM Note 6) suggested that these sequences fell into three categories: 1) unusually prolonged periods of unhappiness (23\% of anomalous sequences), 2) unusually prolonged periods of happiness (48\%), and 3) unusual sequences of high happiness volatility (28\%). We estimated the frequency, duration, and intensity of each of these categories of anomalous sequences and examined how they related to income.

On average, anomalous periods of prolonged unhappiness last two days and occur once every 120 happiness observations (i.e., approximately once a month in our dataset). Income significantly predicts both the frequency $\left(\beta_{\log \text { income }}=-.04, t=-2.89, p=.004\right)$ and intensity (i.e., mean happiness) of these periods $\left(\beta_{\text {log income }}=.10, t=3.51, p<.001\right)$, but not

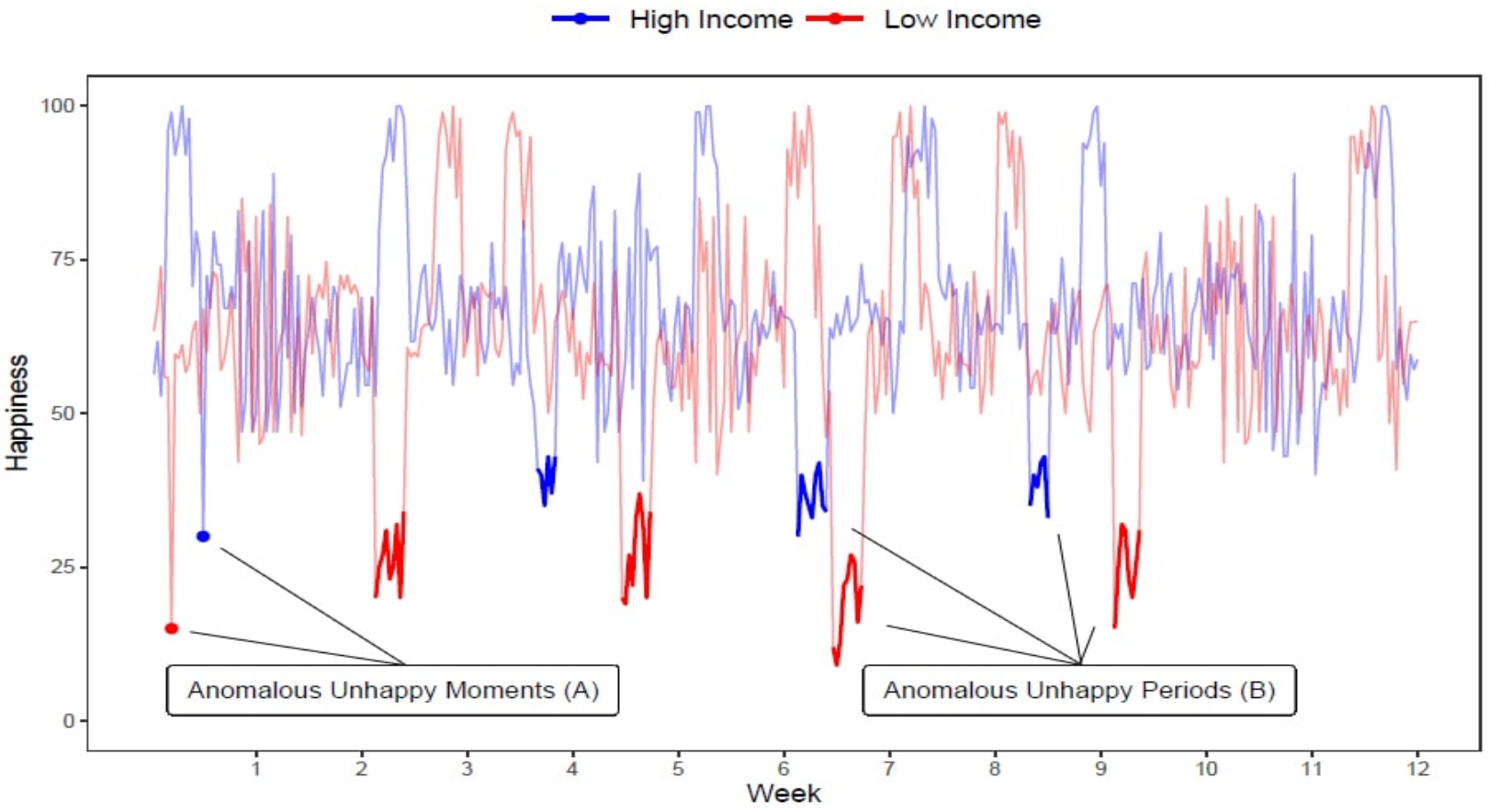

Figure 2: Representative happiness dynamics for low and high-income individuals over three months, based on the average sample parameters. Low-income individuals experience harsher moments of extreme unhappiness (A), as well as more frequent and severe periods of prolonged unhappiness (B). 
their duration $\left(\beta_{\log \text { income }}=.02, t=1.65, p=.09\right)$. For example, the highest income group experienced $30 \%$ fewer prolonged unhappiness periods than the lowest income group. These painful periods were also less extreme overall (mean happiness: 43 vs. 30) - a difference almost three times the size of the gap in average happiness between the two groups (4.5 points).

Anomalous periods of prolonged happiness happened approximately twice a month and typically lasted two days. Periods of unusual volatility occur once every 25 days on average and last for approximately four days. The relationship between income and these types of anomalous sequences was substantially weaker and above a .05 significance cut-off: frequency of prolonged happiness periods ( $\beta_{\log \text { income }}=-.02, t=-1.47, p=.14$ ), average intensity of prolonged happiness periods $\left(\beta_{\log \text { income }}=.04, t=1.95, p=.051\right.$ ), frequency of unusual volatility periods $\left(\beta_{\log \text { income }}=.02, t=1.09, p=.27\right)$, duration of unusual volatility periods $\left(\beta_{\log \text { income }}=-.0015, t=-0.88, p=.37\right)$.

Given the non-linear associations between income and happiness, we performed CAPA analyses separately within the lower-income (less than 3300) and higher-income (more than 3300 euros per month) brackets. Results were in line with the notion of an income plateau: all the CAPA results mentioned above replicated when considering income variation from low to middle income. In contrast, income only predicted the intensity (average happiness) of anomalous sequences of both prolonged unhappiness $\left(\beta_{\text {income }}=.21, t=3.92, p<.001\right)$ and prolonged happiness $\left(\beta_{\text {income }}=.11, t=3.01, p=.003\right)$, when considering income variation from middle to high income.

Taken together, these findings show that people with relatively low income have more volatile emotional lives, as reflected by (1) the experience of more extreme "rock bottom" moments and (2) more frequent and intense periods of lasting unhappiness. Results from the CAPA analyses are robust to alternative, more conventional, ways to identify extreme observations. For example, income significantly relates to people's propensity to experience happiness moments that are in the bottom $1 \%, 5 \%$ or $10 \%$ of the distribution of happi- 
ness observations across and within individuals (see SM Note 7). However, the observational nature of our data precludes causal inferences. To provide suggestive evidence for a causal link between income and happiness volatility, we examined how people's propensity to experience anomalous happiness states changes over the month as a function of income. We reasoned that lower-income individuals might experience more frequent anomalous moments and periods of happiness at times of heightened financial strain (i.e., in the last few days of the months when most Europeans are waiting for their monthly salary). As shown in Fig. 3, income was associated with fewer anomalous affective experiences overall $\left(\beta_{\text {income group }}=-.021, t=-10.56, p<.0001\right)$, and its effect grows larger at the end of the month $\left(e d f_{\text {income group } \mathrm{x} \text { time }}=7.45, p<.0001\right)$. For example, while in the first three weeks of the month, individuals with income 1 S.D. above the mean report $6 \%$ fewer anomalous happiness observations than individuals with income 1 S.D. below the mean (95\% C.I for the relative difference $[4.36 \%, 7.42 \%])$, this difference roughly doubles in the last week $(11.33 \%$ relative difference; $95 \%$ C.I $[9.42 \%, 12.29 \%])$, and triples in last few days of the month $(17 \%$ relative difference; $95 \%$ C.I $[15.19 \%, 18.55 \%])$.

\section{Discussion}

The lay notion that "money buys happiness" has been challenged by decades of empirical research revealing that money has a surprisingly small impact on happiness, especially in wealthier countries (Boyce et al., 2017; Frey and Stutzer, 2002; Kahneman et al., 2006). Accordingly, scholars have recommended that policies should consider alternative ways to increase people's happiness - for example, by focusing not only on economic gains but also income redistribution (Kang and Rhee, 2021; Ono and Lee, 2016).

While these discussions are important, they must be informed by understanding how income shapes our emotional lives. By looking beyond static snapshots of people's happiness, we found that we may have underestimated the impact of income on happiness. Across 


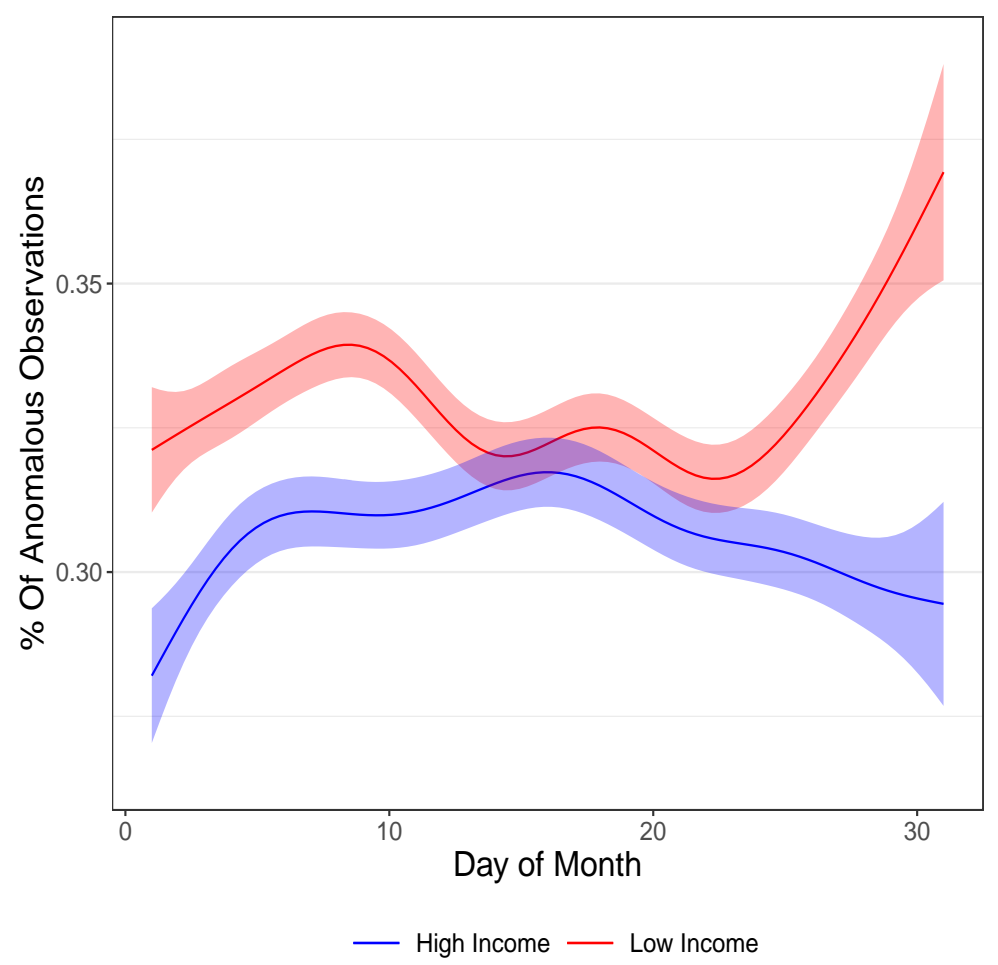

Figure 3: Proportion of anomalous happiness-related observations for individuals with income 1 SD above the mean $(>2900$ euros; in blue) and 1 SD below the mean $(<1100$ euros; in red). Differences between the two groups grow larger towards the end of the month. As in France, salaries and wages are only paid once at the end of the month, results are consistent with the notion that income has a causal effect on happiness volatility.

multiple countries, measurement choices, and model specifications we found a robust negative relationship between financial hardship and people's propensity to experience volatile levels of happiness. This relationship was far from trivial. To put it into perspective, the difference in emotional volatility between the lowest and highest-income group in our European sample $(\Delta=0.4 \mathrm{SD})$ was similar in size to the difference between patients with bipolar disorder and healthy controls ( $\Delta=0.32 \mathrm{SD}$; Stanislaus et al., 2020), and about half the size of the difference between people with and without borderline personality disorder $(\Delta=0.7 \mathrm{SD}$; Ebner-Priemer et al., 2007). And the greatest gap between people of lower and higher income is between how frequent and intense they experience emotional downs, not ups.

The overall impact of relatively rare but extreme episodes of unhappiness on people's lives can live longer than the emotional experience itself. Intense affective states have been 
repeatedly shown to guide people's choices, even when those emotions are incidental to the decision setting. When we feel miserable, we may eat and procrastinate more (Grunberg and Straub, 1992; Tice et al., 2001) and help and trust less (Dunn and Schweitzer, 2005; Manucia et al., 1984). Moreover, the decisions we make based on fleeting emotions can become the basis for future decisions after those emotions have passed. For example, when we make a poor decision out of anger, we tend to repeat that mistake even after cooling off (Andrade and Ariely, 2009).

In line with many other studies (Jebb et al., 2018; Kahneman and Deaton, 2010), we also found strong evidence that the relationship between money and happiness diminishes at higher levels of income. It's important to note that there were also no gains in emotional stability beyond 3,300 euros per month - if anything, the data showed a trend toward decreasing stability.

It's important to note the limitations of the present study. First, while the satiation figure above is consistent with previous research on satiation points in Western Europe (Jebb et al., 2018), we note that determining satiation from categorical income brackets makes it difficult to estimate a precise cutoff. Second, while we found robust associations between income and happiness volatility in a sample of individuals from six developing countries, we could only apply unsupervised anomaly detection techniques to our non-representative experience-sampling dataset from Europe. The relationship between income and the frequency, intensity, or duration of happiness anomalies could differ in the general population. Furthermore, although our data show a stronger connection between income and experienced happiness when people face challenges related to lacking money at the end of the month, it would be valuable to substantiate this "money crunch" hypothesis beyond the time-of-month analysis. Future research should explore, for example, whether money shortages spill over into interpersonal conflict in the family, which may be a more proximal driver of unhappiness. This conjecture is compatible with the observation that income is associated with fluctuations in marital satisfaction rather than overall marital satisfaction (Jackson et al., 
2017).

Money may not buy happiness, but our research strongly suggests that an impoverished life is an emotionally volatile life punctuated with rare - but extreme - moments of distress. While future research is needed to fully assess the personal and social repercussions of income-induced emotional volatility, seemingly rare episodes of misery may only be the beginning - even after the emotional distress itself fades, the suffering is likely to continue in a cascade of repeated poor decisions that set the conditions for social alienation and emotional relapse. Harnessing this knowledge could be useful for public policy. With more and more governments focusing on measuring and increasing happiness (Trudel-Fitzgerald et al., 2019; Verma, 2017), policymakers and researchers may take into consideration not only whether we can increase general happiness but whether we can buy emotional stability. 


\section{References}

aan het Rot, M., Hogenelst, K., \& Schoevers, R. A. (2012). Mood disorders in everyday life: A systematic review of experience sampling and ecological momentary assessment studies. Clinical Psychology Review, 32(6), 510-523. https://doi.org/https://doi. org/10.1016/j.cpr.2012.05.007

Aknin, L. B., Norton, M. I., \& Dunn, E. W. (2009). From wealth to well-being? money matters, but less than people think. The Journal of Positive Psychology, 4(6), 523527. https://doi.org/10.1080/17439760903271421

Andrade, E. B., \& Ariely, D. (2009). The enduring impact of transient emotions on decision making. Organizational Behavior and Human Decision Processes, 109(1), 1-8. https: //doi.org/10.1016/j.obhdp.2009.02.003

Anestis, M. D., Selby, E. A., Crosby, R. D., Wonderlich, S. A., Engel, S. G., \& Joiner, T. E. (2010). A comparison of retrospective self-report versus ecological momentary assessment measures of affective lability in the examination of its relationship with bulimic symptomatology. Behaviour Research and Therapy, 48(7), 607-613. https: //doi.org/10.1016/j.brat.2010.03.012

Berkowitz, L. (1989). Frustration-aggression hypothesis: Examination and reformulation. Psychological Bulletin, 106(1), 59-73. https://doi.org/10.1037/0033-2909.106.1.59

Bowen, R., Clark, M., \& Baetz, M. (2004). Mood swings in patients with anxiety disorders compared with normal controls. Journal of Affective Disorders, 78(3), 185-192. https: //doi.org/10.1016/s0165-0327(02)00304-x 
Boyce, C. J., Daly, M., Hounkpatin, H. O., \& Wood, A. M. (2017). Money may buy happiness, but often so little that it doesn't matter. Psychological Science, 28(4), 544-546. https: //doi.org/10.1177/0956797616672271

Chan, D. K. C., Zhang, X., Fung, H. H., \& Hagger, M. S. (2016). Affect, affective variability, and physical health: Results from a population-based investigation in china. International Journal of Behavioral Medicine, 23(4), 438-446. https://doi.org/10.1007/ s12529-015-9510-2

Ciccarelli, M., Griffiths, M. D., Nigro, G., \& Cosenza, M. (2017). Decision making, cognitive distortions and emotional distress: A comparison between pathological gamblers and healthy controls. Journal of Behavior Therapy and Experimental Psychiatry, 54, 204210. https://doi.org/10.1016/j.jbtep.2016.08.012

Daly, M., \& Kelly, G. (2015). Families and poverty: Everyday life on a low income. Policy Press.

Dejonckheere, E., Mestdagh, M., Houben, M., Rutten, I., Sels, L., Kuppens, P., \& Tuerlinckx, F. (2019). Complex affect dynamics add limited information to the prediction of psychological well-being. Nature Human Behaviour, 3(5), 478-491. https://doi.org/ $10.1038 / \mathrm{s} 41562-019-0555-0$

Dunn, J. R., \& Schweitzer, M. E. (2005). Feeling and believing: The influence of emotion on trust. Journal of Personality and Social Psychology, 88(5), 736-748. https://doi.org/ 10.1037/0022-3514.88.5.736

Ebner-Priemer, U. W., Kuo, J., Kleindienst, N., Welch, S. S., Reisch, T., Reinhard, I., Lieb, K., Linehan, M. M., \& Bohus, M. (2007). State affective instability in borderline per- 
sonality disorder assessed by ambulatory monitoring. Psychological Medicine, 37(7), 961-970. https://doi.org/10.1017/s0033291706009706

Fisch, A. T. M., Eckley, I. A., \& Fearnhead, P. (2019). A linear time method for the detection of point and collective anomalies [arXiv: 1806.01947]. arXiv:1806.01947 [cs, stat]. http://arxiv.org/abs/1806.01947

Frey, B. S., \& Stutzer, A. (2002). What can economists learn from happiness research? Journal of Economic Literature, 40(2), 402-435. https://doi.org/10.1257/jel.40.2.402

Golier, J., Yehuda, R., Schmeidler, J., \& Siever, L. (2001). Variability and severity of depression and anxiety in post traumatic stress disorder and major depressive disorder. Depression and Anxiety, 13(2), 97-100. https://doi.org/10.1002/da.1022

Gratz, K. (2003). Risk factors for and functions of deliberate self-harm: An empirical and conceptual review. Clinical Psychology: Science and Practice, 10, 192-205. https: //doi.org/10.1093/clipsy.bpg022

Grunberg, N. E., \& Straub, R. O. (1992). The role of gender and taste class in the effects of stress on eating. Health Psychology, 11(2), 97-100. https://doi.org/10.1037/02786133.11.2.97

Hardy, J., \& Segerstrom, S. C. (2017). Intra-individual variability and psychological flexibility: Affect and health in a national us sample. Journal of Research in Personality, 69, 13-21. https://doi.org/10.1016/j.jrp.2016.04.002

Hastie, T., \& Tibshirani, R. (1987). Generalized additive models: Some applications. Journal of the American Statistical Association, 82(398), 371-386. http://www.jstor.org/ stable/2289439 
Houben, M., Van Den Noortgate, W., \& Kuppens, P. (2015). The relation between shortterm emotion dynamics and psychological well-being: A meta-analysis. Psychological Bulletin, 141(4), 901-930. https://doi.org/10.1037/a0038822

Hull, J. G., Young, R. D., \& Jouriles, E. (1986). Applications of the self-awareness model of alcohol consumption: Predicting patterns of use and abuse. Journal of Personality and Social Psychology, 51(4), 790-796. https://doi.org/10.1037/0022-3514.51.4.790

Jackson, G. L., Krull, J. L., Bradbury, T. N., \& Karney, B. R. (2017). Household income and trajectories of marital satisfaction in early marriage. Journal of Marriage and Family, 79(3), 690-704. https://doi.org/https://doi.org/10.1111/jomf.12394

Jantsch, A., \& Veenhoven, R. (2019). Private wealth and happiness - a research synthesis using an online findings-archive. https://doi.org/10.1007/978-3-030-05535-6_2

Jebb, A. T., Tay, L., Diener, E., \& Oishi, S. (2018). Happiness, income satiation and turning points around the world. Nature Human Behaviour, 2(1), 33-38. https://doi.org/10. 1038/s41562-017-0277-0

Jenkins, B. N., Hunter, J. F., Cross, M. P., Acevedo, A. M., \& Pressman, S. D. (2018). When is affect variability bad for health? the association between affect variability and immune response to the influenza vaccination. Journal of Psychosomatic Research, 104, 41-47. https://doi.org/10.1016/j.jpsychores.2017.11.002

Jones, S., Hare, D., \& Evershed, K. (2005). Actigraphic assessment of circadian activity and sleep patterns in bipolar disorder. Bipolar Disorders, 7(2), 176-186. https://doi.org/ 10.1111/j.1399-5618.2005.00187.x 
Kahneman, D., \& Deaton, A. (2010). High income improves evaluation of life but not emotional well-being. Proceedings of the National Academy of Sciences, 107(38), 1648916493. https://doi.org/10.1073/pnas.1011492107

Kahneman, D., Krueger, A. B., Schkade, D., Schwarz, N., \& Stone, A. A. (2006). Would you be happier if you were richer? a focusing illusion. Science, 312(5782), 1908-1910. https://doi.org/10.1126/science.1129688

Kang, H., \& Rhee, D.-E. (2021). Does income (re)distribution matter for subjective wellbeing? evidence from cross-country panel data. Social Science Quarterly, 102(2), 706721. https://doi.org/10.1111/ssqu.12943

Killingsworth, M. A. (2021). Experienced well-being rises with income, even above $\$ 75,000$ per year. Proceedings of the National Academy of Sciences, 118(4). https://doi.org/ $10.1073 /$ pnas. 2016976118

Koval, P., Ogrinz, B., Kuppens, P., Van den Bergh, O., Tuerlinckx, F., \& Sütterlin, S. (2013). Affective instability in daily life is predicted by resting heart rate variability. PLOS ONE, 8(11), null. https://doi.org/10.1371/journal.pone.0081536

Kuppens, P. (2015). It's About Time: A Special Section on Affect Dynamics. Emotion Review, 7(4), 297-300. https://doi.org/10.1177/1754073915590947

Kuppens, P., \& Verduyn, P. (2017). Emotion dynamics. Current Opinion in Psychology, 17, 22-26. https://doi.org/10.1016/j.copsyc.2017.06.004

Lakner, C., Yonzan, N., Gerszon Mahler, D., Castaneda Aguilar, R. A., \& Wu, H. (2021). Updated estimates of the impact of covid-19 on global poverty: Looking back at 2020 and the outlook for 2021. https://blogs.worldbank.org/opendata/updated-estimatesimpact-covid-19-global-poverty-looking-back-2020-and-outlook-2021 
Manucia, G. K., Baumann, D. J., \& Cialdini, R. B. (1984). Mood influences on helping: Direct effects or side effects? Journal of Personality and Social Psychology, 46(2), 357-364. https://doi.org/10.1037/0022-3514.46.2.357

Masheb, R. M., \& Grilo, C. M. (2006). Emotional overeating and its associations with eating disorder psychopathology among overweight patients with binge eating disorder. International Journal of Eating Disorders, 39(2), 141-146. https://doi.org/10.1002/ eat. 20221

Mayer, M. (2019). Missranger: Fast imputation of missing values [R package version 2.1.0]. https://CRAN.R-project.org/package=missRanger

McConville, C., \& Cooper, C. (1996). Mood variability and the intensity of depressive states. Current Psychology, 14(4), 329-338. https://doi.org/10.1007/bf02686921

Mckeown, G. J., \& Sneddon, I. (2014). Modeling continuous self-report measures of perceived emotion using generalized additive mixed models. Psychological Methods, 19(1), 155174. https://doi.org/10.1037/a0034282

Mestdagh, M., Pe, M., Pestman, W., Verdonck, S., Kuppens, P., \& Tuerlinckx, F. (2018). Sidelining the mean: The relative variability index as a generic mean-corrected variability measure for bounded variables. Psychological Methods, 23(4), 690-707. https: //doi.org/10.1037/met0000153

Morduch, J. (1994). Poverty and vulnerability. The American Economic Review, 84 (2), 221225. http://www.jstor.org/stable/2117833

Murray, C. J., Ezzati, M., Flaxman, A. D., Lim, S., Lozano, R., Michaud, C., Naghavi, M., Salomon, J. A., Shibuya, K., Vos, T., et al. (2012). Gbd 2010: Design, definitions, and metrics. The Lancet, 380(9859), 2063-2066. 
OECD. (2011). How's life? : Measuring well-being. https:// documents . worldbank.org/ en/publication/documents-reports/documentdetail/127381468326701628/hows-lifemeasuring-well-being

Ono, H., \& Lee, K. S. (2016). Redistributing happiness: How social policies shape life satisfaction. Praeger, an imprint of ABC-CLIO, LLC.

Pfaltz, M. C., Michael, T., Grossman, P., Margraf, J., \& Wilhelm, F. H. (2010). Instability of physical anxiety symptoms in daily life of patients with panic disorder and patients with posttraumatic stress disorder. Journal of Anxiety Disorders, 24(7), 792-798. https://doi.org/10.1016/j.janxdis.2010.06.001

Pirla, S., Taquet, M., \& Quoidbach, J. (2021). Measuring affect dynamics: An empirical framework. https://doi.org/10.31219/osf.io/x2ywa

Quoidbach, J., Taquet, M., Desseilles, M., de Montjoye, Y.-A., \& Gross, J. J. (2019). Happiness and social behavior [PMID: 31268832]. Psychological Science, 30(8), 1111-1122. https://doi.org/10.1177/0956797619849666

Röcke, C., Li, S.-C., \& Smith, J. (2009). Intraindividual variability in positive and negative affect over 45 days: Do older adults fluctuate less than young adults? Psychology and Aging, 24(4), 863-878. https://doi.org/10.1037/a0016276

Santangelo, P., Reinhard, I., Mussgay, L., Steil, R., Sawitzki, G., Klein, C., Trull, T. J., Bohus, M., \& Ebner-Priemer, U. W. (2014). Specificity of affective instability in patients with borderline personality disorder compared to posttraumatic stress disorder, bulimia nervosa, and healthy controls. Journal of Abnormal Psychology, 123(1), 258272. https://doi.org/10.1037/a0035619 
Schenker, N., Raghunathan, T. E., Chiu, P.-L., Makuc, D. M., Zhang, G., \& Cohen, A. J. (2006). Multiple imputation of missing income data in the national health interview survey. Journal of the American Statistical Association, 101(475), 924-933. https: //doi.org/10.1198/016214505000001375

Servaas, M. N., Riese, H., Renken, R. J., Wichers, M., Bastiaansen, J. A., Figueroa, C. A., Geugies, H., Mocking, R. J., Geerligs, L., Marsman, J.-B. C., Aleman, A., Schene, A. H., Schoevers, R. A., \& Ruhé, H. G. (2017). Associations Between Daily Affective Instability and Connectomics in Functional Subnetworks in Remitted Patients with Recurrent Major Depressive Disorder. Neuropsychopharmacology, 42(13), 2583-2592. https://doi.org/10.1038/npp.2017.65

Simonsohn, U. (2018). Two lines: A valid alternative to the invalid testing of u-shaped relationships with quadratic regressions. Advances in Methods and Practices in Psychological Science, 1(4), 538-555. https://doi.org/10.1177/2515245918805755

Simonsohn, U., Simmons, J. P., \& Nelson, L. D. (2020). Specification curve analysis. Nature Human Behaviour, 4 (11), 1208-1214. https://doi.org/10.1038/s41562-020-0912-z

Snir, A., Bar-Kalifa, E., Berenson, K. R., Downey, G., \& Rafaeli, E. (2017). Affective instability as a clinical feature of avoidant personality disorder. Personality Disorders: Theory, Research, and Treatment, 8(4), 389-395. https://doi.org/10.1037/per0000202

Stanislaus, S., Faurholt-Jepsen, M., Vinberg, M., Coello, K., Kjærstad, H. L., Melbye, S., Sletved, K. S., Christensen, E. M., Frost, M., Bardram, J. E., \& Kessing, L. V. (2020). Mood instability in patients with newly diagnosed bipolar disorder, unaffected relatives, and healthy control individuals measured daily using smartphones. Journal of Affective Disorders, 271, 336-344. https://doi.org/https://doi.org/10.1016/j.jad. 2020.03.049 
Tan, J. J. X., Kraus, M. W., Carpenter, N. C., \& Adler, N. E. (2020). The association between objective and subjective socioeconomic status and subjective well-being: A meta-analytic review. Psychological Bulletin, 146(11), 970-1020. https://doi.org/10. $1037 /$ bul0000258

Thompson, R., Mata, J., Jaeggi, S., Buschkuehl, M., Jonides, J., \& Gotlib, I. (2012). The everyday emotional experience of adults with major depressive disorder: Examining emotional instability, inertia, and reactivity. Journal of Abnormal Psychology, 121(4), 819-829. https://doi.org/10.1037/a0027978

Tice, D. M., Bratslavsky, E., \& Baumeister, R. F. (2001). Emotional distress regulation takes precedence over impulse control: If you feel bad, do it! Journal of Personality and Social Psychology, 80(1), 53-67. https://doi.org/10.1037/0022-3514.80.1.53

Trudel-Fitzgerald, C., Millstein, R. A., Hippel, C. V., Howe, C. J., Tomasso, L. P., Wagner, G. R., \& Vanderweele, T. J. (2019). Psychological well-being as part of the public health debate? insight into dimensions, interventions, and policy. BMC Public Health, 19(1). https://doi.org/10.1186/s12889-019-8029-x

UN. (2012). Happiness : Towards a holistic approach to development. https://digitallibrary. un.org/record $/ 715187 ? \ln =$ en

Verma, R. (2017). Gross national happiness: Meaning, measure and degrowth in a living development alternative. Journal of Political Ecology, 24(1). https:// doi.org/10. $2458 / \mathrm{v} 24 \mathrm{i} 1.20885$

Vos, T., Allen, C., Arora, M., Barber, R. M., Bhutta, Z. A., Brown, A., Carter, A., Casey, D. C., Charlson, F. J., Chen, A. Z., et al. (2016). Global, regional, and national incidence, prevalence, and years lived with disability for 310 diseases and injuries, 
1990-2015: A systematic analysis for the global burden of disease study 2015. The Lancet, 388(10053), 1545-1602.

Wood, S. N. (2003). Thin-plate regression splines. Journal of the Royal Statistical Society (B), $65(1), 95-114$.

Wood, S. N., \& Augustin, N. (2002). Gams with integrated model selection using penalized regression splines and applications to environmental modelling. Ecological Modelling, $157,157-177$.

Zeigler-Hill, V., \& Abraham, J. (2006). Borderline Personality Features: Instability of Self-Esteem and Affect. Journal of Social and Clinical Psychology, 25(6), 668-687. https://doi. org/10.1521/jscp.2006.25.6.668 


\section{Supplemental Materials:}

\section{Note 1: Summary Statistics}

Table S1 and S2 present the summary statistics of our "58 seconds" data. In Table S3 we present the distribution of income responses before $\left(N_{\text {Raw }}=6,010\right)$ and after our main imputation by Random Forests $\left(N_{R F}=23,471\right)$. Table $\mathrm{S} 4$ and Table S5 present the summary statistics for the World Health Organization SAGE dataset $(N=25,739$ including 105 observations with missing values for income).

Table S1: Summary Statistics - continuous variables in the "58 seconds" dataset.

\begin{tabular}{lccc}
\hline \hline Numeric Variable & Average & SD & Median \\
\hline Age & 27.905 & 9.215 & 26 \\
Income (in EUR/month) & $1,243.134$ & $1,350.856$ & 1,200 \\
Average Happiness & 62.555 & 16.657 & 63.176 \\
Happiness SD & 16.429 & 6.727 & 15.484 \\
Happiness Rel. SD & 0.371 & 0.152 & 0.351 \\
Happiness RMSSD & 19.621 & 8.759 & 18.137 \\
Happiness TKEO & 249.772 & 240.404 & 185.226 \\
Happiness PAC & 0.125 & 0.125 & 0.091 \\
\hline
\end{tabular}

Table S2: Summary Statistics - categorical variables in the "58 seconds" dataset.

\begin{tabular}{lccc}
\hline \hline Categorical Variable & Category & $\mathrm{N}$ & Sample Proportion \\
\hline Gender & Female & 16,065 & $68.4 \%$ \\
Gender & Male & 7,406 & $31.6 \%$ \\
Country & France & 22,040 & $93.9 \%$ \\
Country & Switzerland & 866 & $3.6 \%$ \\
Country & Austria & 339 & $1.4 \%$ \\
Country & Belgium & 135 & $0.06 \%$ \\
Country & Other & 1 & $0 \%$ \\
\hline
\end{tabular}


Table S3: Distribution of income responses in the "58 seconds" dataset.

\begin{tabular}{lcccc}
\hline & \multicolumn{2}{c}{ Raw Responses } & \multicolumn{2}{c}{ RF Imputation } \\
\cline { 2 - 5 } Monthly Income & Obs. & Rel. Freq. & Obs. & Rel. Freq. \\
\hline No income & 1630 & $27.1 \%$ & 5988 & $25.5 \%$ \\
Less than 1100 eur. & 1121 & $18.7 \%$ & 4843 & $20.6 \%$ \\
Between 1100 and 1300 eur. & 628 & $10.4 \%$ & 2691 & $11.5 \%$ \\
Between 1300 and 1400 eur. & 236 & $3.9 \%$ & 997 & $4.2 \%$ \\
Between 1400 and 1500 eur. & 279 & $4.6 \%$ & 1054 & $4.5 \%$ \\
Between 1500 and 1700 eur. & 425 & $7.1 \%$ & 1686 & $7.1 \%$ \\
Between 1700 and 1900 eur. & 327 & $5.4 \%$ & 1329 & $5.6 \%$ \\
Between 1900 and 2100 eur. & 285 & $4.7 \%$ & 1168 & $4.9 \%$ \\
Between 2100 and 2500 eur. & 345 & $5.7 \%$ & 1336 & $5.6 \%$ \\
Between 2500 and 3300 eur. & 345 & $5.7 \%$ & 1216 & $5.1 \%$ \\
Between 3300 and 4500 eur. & 191 & $3.2 \%$ & 575 & $2.4 \%$ \\
Between 4500 and 7500 eur. & 129 & $2.1 \%$ & 383 & $1.6 \%$ \\
More than 7500 eur. & 69 & $1.1 \%$ & 205 & $0.8 \%$ \\
\hline
\end{tabular}

Table S4: Summary Statistics - numeric variables in the WHO SAGE dataset.

\begin{tabular}{lccc}
\hline \hline Numeric variables & Average & SD & Median \\
\hline Age & 43.015 & 14.737 & 44 \\
Income (ladder) & 0.335 & 0.561 & 0.295 \\
Average Happiness & 1.324 & 0.621 & 1.400 \\
Happiness SD & 0.331 & 0.322 & 0.289 \\
Happiness Rel. SD & 0.313 & 0.327 & 0.242 \\
Happiness RMSSD & 0.439 & 0.439 & 0.377 \\
Happiness TKEO & 0.129 & 0.323 & 0 \\
Happiness PAC & 0.084 & 0.189 & 0 \\
\hline
\end{tabular}

Table S5: Summary Statistics - categorical variables in the WHO SAGE dataset.

\begin{tabular}{lccc}
\hline \hline Categorical Variable & Category & $\mathrm{N}$ & Sample Proportion \\
\hline Gender & Female & 14,567 & $56.7 \%$ \\
Gender & Male & 11,130 & $43.3 \%$ \\
Country & China & 9,131 & $35.4 \%$ \\
Country & Ghana & 3,162 & $12.3 \%$ \\
Country & India & 8,223 & $31.9 \%$ \\
Country & Mexico & 646 & $2.5 \%$ \\
Country & Russia & 2,082 & $8.1 \%$ \\
Country & South Africa & 2,495 & $9.7 \%$ \\
\hline
\end{tabular}




\section{Note 2: Formal Definitions of Happiness Fluctuations}

Table S6 presents the formal definitions of the different operationalizations of happiness fluctuations included in our studies. In our formulas, $x_{i}$ stands for the $i^{\text {th }}$ happiness observation of a given individual. $\mathrm{M}, \mathrm{SD}$, and $\mathrm{n}$ represent an individual average happiness, standard deviation in happiness and total number of happiness reports. Finally, $I\left(x_{i+1}-x_{i}, d_{0.9}\right)$ defines a binary variable taking a value of 1 if the absolute value of $\left(x_{i+1}-x_{i}\right)$ is greater than $d_{0.9}$ and 0 otherwise, where $d_{0.9}$ represents the $90^{\text {th }}$ percentile in the distribution of absolute happiness changes across all participants.

Table S6: Operationalizations of Happiness Fluctuations.

\section{Index}

Standard Deviation (SD)

Relative Standard Deviation

(Rel. SD)

Root Mean Square of

Successive Differences (RMSSD)

Teager-Kaiser energy operator (TKEO)

\section{Formal Definition Interpretation}

$$
\sqrt{\frac{\sum\left(x_{i}-M\right)^{2}}{n}} \quad \text { Variability in happiness reports. }
$$

Mean-corrected estimate of the standard deviation for bounded variables (Mestdagh et al. 2018).

$\frac{S D}{\max (S D \mid M)}$

Probability of Acute Change

$(\mathrm{PAC})$ $\sqrt{\frac{\sum\left(x_{i}-x_{(i+1)}\right)^{2}}{n-1}}$

$\frac{\sum\left(x_{i}^{2}-x_{(i-1)} x_{(i+1)}\right)}{n-2}$

$\frac{\sum I\left(x_{i+1}-x_{i}, d_{0.9}\right)}{n-1}$

Likelihood of extreme change in happiness.
Average change across successive happiness observations.

Average change across 3 happiness reports. Useful in identifying happiness spikes. 


\section{Note 3: Main Results - Robustness Checks}

In this section, we show the robustness of our results to multiple specifications. These robustness checks are performed using our "58 seconds" data (with missing income observations imputed by a random forest approach). As in the main body of the paper, all our models exclude the data from participants that reported having no income or an income of over 7,500 euros per month $(\mathrm{N}=17,278)$. Further robustness checks are presented in the next section (SM Note 4). In order to accommodate the non-linear nature of the relationship between income and happiness volatility, our main results are estimated using Generalized Additive Models (GAMs). All our models use income as the main explanatory variable. Each model uses a different measure of average happiness or happiness volatility as the dependent variable. Table S7 presents the extension of our main results to all operationalizations of happiness fluctuations. Table S8 shows that these relations are significant when controlling for demographic variables. Table S9 shows that these relations remain significant when, in addition to demographic variables, we control for the effect of income on average happiness. As the GAM coefficients are not directly interpretable, in tables S10-S12, we present the same analyses using Linear Regressions (OLS) and the logarithm of income as the main explanatory variable. To allow for comparisons across specifications, we report the standardized regression coefficients (with standard errors in parenthesis) for all numeric variables (log income, age, average happiness). For binary variables (gender), we report the coefficients obtained when regressing this raw variables on the standardized dependent variable. We also present visually the results of the GAM models (with income as a unique explanatory variable) in Figure S1. 
Table S7: GAM results.

\begin{tabular}{lcccccc}
\hline \hline & \multicolumn{5}{c}{ Dependent variable: } \\
\cline { 2 - 6 } & Average & SD & Rel.SD & RMSSD & TKEO & PAC \\
& $(1)$ & $(2)$ & $(3)$ & $(4)$ & $(3)$ & $(4)$ \\
\hline Income Statistics: & & & & & \\
Edf & 3.754 & 2.933 & 2.776 & 2.991 & 2.915 & 2.889 \\
Ref.df & 4.474 & 3.554 & 3.375 & 3.620 & 3.534 & 3.505 \\
F & 22.752 & 111.261 & 74.861 & 102.915 & 85.979 & 90.811 \\
P Value & & & & & & \\
C.00001 & $<.00001$ & $<.00001$ & $<.00001$ & $<.00001$ & $<.00001$ \\
\hline
\end{tabular}

Table S8: GAM results (controlling for age, gender and country of residence).

\begin{tabular}{lcccccc}
\hline \hline & \multicolumn{5}{c}{ Dependent variable: } \\
\cline { 2 - 6 } & Average & SD & Rel.SD & RMSSD & TKEO & PAC \\
& $(1)$ & $(2)$ & $(3)$ & $(4)$ & $(3)$ & $(4)$ \\
\hline Income Statistics: & & & & & \\
Edf & 3.750 & 2.483 & 2.284 & 2.243 & 2.255 & 2.168 \\
Ref.df & 4.472 & 3.042 & 2.808 & 2.761 & 2.775 & 2.672 \\
F & 14.097 & 16.405 & 8.162 & 11.876 & 12.502 & 11.544 \\
P Value & & & & & & \\
\hline
\end{tabular}


Table S9: GAM results (controlling for age, gender, country of residence and average happiness).

\begin{tabular}{lcccccc}
\hline \hline & \multicolumn{6}{c}{ Dependent variable: } \\
\cline { 2 - 7 } & Average & $\mathrm{SD}$ & Rel.SD & RMSSD & TKEO & PAC \\
& $(1)$ & $(2)$ & $(3)$ & $(4)$ & $(3)$ & $(4)$ \\
\hline Income Statistics: & & & & & & \\
Edf & - & 2.401 & 2.430 & 2.081 & 2.153 & 1.966 \\
Ref.df & - & 2.945 & 2.979 & 2.569 & 2.655 & 2.434 \\
F & - & 12.14 & 12.93 & 9.12 & 9.725 & 8.095 \\
P Value & - & $<.00001$ & $<.00001$ & .00003 & .00001 & .00012 \\
\hline
\end{tabular}

Table S10: Linear regression results.

\begin{tabular}{|c|c|c|c|c|c|c|}
\hline & \multicolumn{6}{|c|}{ Dependent variable: } \\
\hline & Average & $\mathrm{SD}$ & Rel.SD & RMSSD & TKEO & $\mathrm{PAC}$ \\
\hline & $(1)$ & $(2)$ & $(3)$ & $(4)$ & $(5)$ & $(6)$ \\
\hline Log Income & $\begin{array}{c}0.075^{* * *} \\
(0.008)\end{array}$ & $\begin{array}{c}-0.148^{* * *} \\
(0.008)\end{array}$ & $\begin{array}{c}-0.119^{* * *} \\
(0.008)\end{array}$ & $\begin{array}{c}-0.145^{* * *} \\
(0.008)\end{array}$ & $\begin{array}{c}-0.131^{* * *} \\
(0.008)\end{array}$ & $\begin{array}{c}-0.135^{* * *} \\
(0.008)\end{array}$ \\
\hline Constant & $\begin{array}{l}-0.000 \\
(0.008)\end{array}$ & $\begin{array}{c}0.000 \\
(0.008)\end{array}$ & $\begin{array}{c}0.000 \\
(0.008)\end{array}$ & $\begin{array}{c}0.000 \\
(0.008)\end{array}$ & $\begin{array}{c}0.000 \\
(0.008)\end{array}$ & $\begin{array}{l}-0.000 \\
(0.008)\end{array}$ \\
\hline Observations & 17,278 & 17,278 & 17,278 & 17,278 & 17,278 & 17,278 \\
\hline $\mathrm{R}^{2}$ & 0.006 & 0.022 & 0.014 & 0.021 & 0.017 & 0.018 \\
\hline Adjusted $\mathrm{R}^{2}$ & 0.006 & 0.022 & 0.014 & 0.021 & 0.017 & 0.018 \\
\hline Residual Std. Error & 0.997 & 0.989 & 0.993 & 0.989 & 0.991 & 0.991 \\
\hline F Statistic & $98.041^{* * *}$ & $389.327^{* * *}$ & $250.016^{* * *}$ & $370.598^{* * *}$ & $303.050^{* * *}$ & $318.299^{* * *}$ \\
\hline
\end{tabular}


Table S11: Linear regression results (controlling for age, gender and country of residence).

\begin{tabular}{|c|c|c|c|c|c|c|}
\hline & \multicolumn{6}{|c|}{ Dependent variable: } \\
\hline & Average & SD & Rel.SD & RMSSD & TKEO & PAC \\
\hline & $(1)$ & $(2)$ & $(3)$ & $(4)$ & $(5)$ & $(6)$ \\
\hline Log Income & $\begin{array}{c}0.061^{* * *} \\
(0.008)\end{array}$ & $\begin{array}{c}-0.063^{* * *} \\
(0.008)\end{array}$ & $\begin{array}{c}-0.048^{* * *} \\
(0.008)\end{array}$ & $\begin{array}{c}-0.054^{* * *} \\
(0.008)\end{array}$ & $\begin{array}{c}-0.056^{* * *} \\
(0.008)\end{array}$ & $\begin{array}{c}-0.053^{* * *} \\
(0.008)\end{array}$ \\
\hline Age & $\begin{array}{c}0.010 \\
(0.008)\end{array}$ & $\begin{array}{c}-0.204^{* * *} \\
(0.008)\end{array}$ & $\begin{array}{c}-0.183^{* * *} \\
(0.008)\end{array}$ & $\begin{array}{c}-0.228^{* * *} \\
(0.008)\end{array}$ & $\begin{array}{c}-0.188^{* * *} \\
(0.008)\end{array}$ & $\begin{array}{c}-0.203^{* * *} \\
(0.008)\end{array}$ \\
\hline Male & $\begin{array}{c}0.140^{* * *} \\
(0.016)\end{array}$ & $\begin{array}{c}-0.131^{* * *} \\
(0.016)\end{array}$ & $\begin{array}{c}-0.058^{* * *} \\
(0.016)\end{array}$ & $\begin{array}{c}-0.080^{* * *} \\
(0.016)\end{array}$ & $\begin{array}{c}-0.071^{* * *} \\
(0.016)\end{array}$ & $\begin{array}{c}-0.063^{* * *} \\
(0.016)\end{array}$ \\
\hline Constant & $\begin{array}{l}-0.102 \\
(0.117)\end{array}$ & $\begin{array}{c}0.112 \\
(0.114)\end{array}$ & $\begin{array}{c}0.071 \\
(0.115)\end{array}$ & $\begin{array}{c}0.064 \\
(0.114)\end{array}$ & $\begin{array}{c}0.088 \\
(0.115)\end{array}$ & $\begin{array}{l}-0.009 \\
(0.115)\end{array}$ \\
\hline Observations & 17,278 & 17,278 & 17,278 & 17,278 & 17,278 & 17,278 \\
\hline $\mathrm{R}^{2}$ & 0.012 & 0.061 & 0.044 & 0.066 & 0.048 & 0.054 \\
\hline Adjusted $\mathrm{R}^{2}$ & 0.011 & 0.060 & 0.043 & 0.066 & 0.048 & 0.054 \\
\hline Residual Std. Error & 0.994 & 0.969 & 0.978 & 0.966 & 0.976 & 0.973 \\
\hline F Statistic & $25.449^{* * *}$ & $139.792^{* * *}$ & $98.342^{* * *}$ & $153.576^{* * *}$ & $109.280^{* * *}$ & $123.612^{* * *}$ \\
\hline
\end{tabular}


Table S12: Linear regression results (controlling for age, gender, country of residence and average happiness).

\begin{tabular}{|c|c|c|c|c|c|c|}
\hline & \multicolumn{6}{|c|}{ Dependent variable: } \\
\hline & Average & $\mathrm{SD}$ & Rel.SD & RMSSD & TKEO & $\mathrm{PAC}$ \\
\hline & $(1)$ & $(2)$ & (3) & (4) & $(5)$ & $(6)$ \\
\hline Log Income & $\begin{array}{c}0.061^{* * *} \\
(0.008)\end{array}$ & $\begin{array}{c}-0.055^{* * *} \\
(0.008)\end{array}$ & $\begin{array}{c}-0.056^{* * *} \\
(0.008)\end{array}$ & $\begin{array}{c}-0.047^{* * *} \\
(0.008)\end{array}$ & $\begin{array}{c}-0.050^{* * *} \\
(0.008)\end{array}$ & $\begin{array}{c}-0.044^{* * *} \\
(0.008)\end{array}$ \\
\hline Average Happiness & & $\begin{array}{c}-0.134^{* * *} \\
(0.007)\end{array}$ & $\begin{array}{c}0.138^{* * *} \\
(0.007)\end{array}$ & $\begin{array}{c}-0.113^{* * *} \\
(0.007)\end{array}$ & $\begin{array}{c}-0.096^{* * *} \\
(0.007)\end{array}$ & $\begin{array}{c}-0.147^{* * *} \\
(0.007)\end{array}$ \\
\hline Age & $\begin{array}{c}0.010 \\
(0.008)\end{array}$ & $\begin{array}{c}-0.203^{* * *} \\
(0.008)\end{array}$ & $\begin{array}{c}-0.184^{* * *} \\
(0.008)\end{array}$ & $\begin{array}{c}-0.227^{* * *} \\
(0.008)\end{array}$ & $\begin{array}{c}-0.187^{* * *} \\
(0.008)\end{array}$ & $\begin{array}{c}-0.201^{* * *} \\
(0.008)\end{array}$ \\
\hline Male & $\begin{array}{c}0.140^{* * *} \\
(0.016)\end{array}$ & $\begin{array}{c}-0.112^{* * *} \\
(0.016)\end{array}$ & $\begin{array}{c}-0.077^{* * *} \\
(0.016)\end{array}$ & $\begin{array}{c}-0.064^{* * *} \\
(0.016)\end{array}$ & $\begin{array}{c}-0.058^{* * *} \\
(0.016)\end{array}$ & $\begin{array}{c}-0.043^{* * *} \\
(0.016)\end{array}$ \\
\hline Constant & $\begin{array}{l}-0.102 \\
(0.117)\end{array}$ & $\begin{array}{c}0.098 \\
(0.113)\end{array}$ & $\begin{array}{c}0.085 \\
(0.114)\end{array}$ & $\begin{array}{c}0.052 \\
(0.113)\end{array}$ & $\begin{array}{c}0.078 \\
(0.115)\end{array}$ & $\begin{array}{l}-0.024 \\
(0.114)\end{array}$ \\
\hline Observations & 17,278 & 17,278 & 17,278 & 17,278 & 17,278 & 17,278 \\
\hline $\mathrm{R}^{2}$ & 0.012 & 0.079 & 0.062 & 0.079 & 0.057 & 0.076 \\
\hline Adjusted $\mathrm{R}^{2}$ & 0.011 & 0.078 & 0.062 & 0.079 & 0.057 & 0.075 \\
\hline Residual Std. Error & 0.994 & 0.960 & 0.969 & 0.960 & 0.971 & 0.962 \\
\hline F Statistic & $25.449^{* * *}$ & $163.890^{* * *}$ & $127.779^{* * *}$ & $164.903^{* * *}$ & $116.594^{* * *}$ & $156.693^{* * *}$ \\
\hline
\end{tabular}



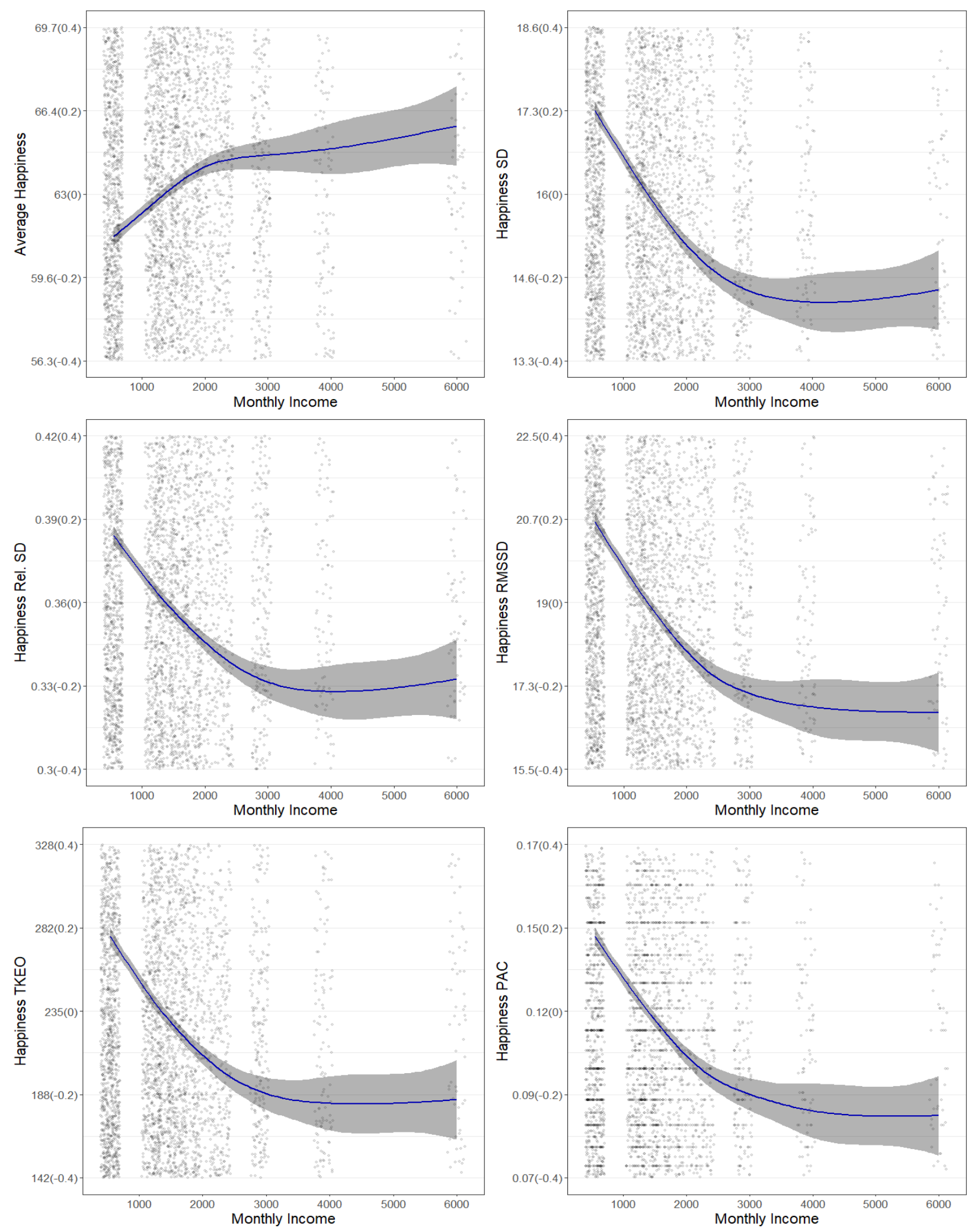

Figure S1: GAM Fit with 95\% C.I. (in gray). 
In the main manuscript, we claim that the effect of income on happiness volatility satiated at a monthly income of 3,000 euros. To estimate this satiation point, we used the confidence intervals of the derivatives of the GAM splines (estimated in a model with income as the unique explanatory variable). Figure S2 presents the 95\% confidence intervals of the splines' derivatives for each of our GAM models. To identify the precise satiation points, we found the lowest income level that corresponded to a spline derivative containing a slope of 0 in its $95 \%$ confidence interval. The specific satiation points were found at 2,111.05 euros per month for average happiness, 3,069.6 euros for happiness SD, 3,042.21 euros for the relative SD, 2,987.44 euros for RMSSD, 2,960.05 euros for TKEO and 2,768.34 euros for PAC. As stated in the main body of the paper, we also analyzed our data using separate linear regressions for low and high-income individuals. To separate our sample based on income, we made use of the Robin Hood algorithm (Simonsohn, 2018). Following the algorithm results, we estimated two regression lines, one for low-income individuals and one for high income individuals. The Robin Hood algorithm suggested using a cutoff income of 2,000 euros per month for the analysis of average happiness and 2,300 euros for all analyses of happiness volatility. Note that this amount is not the satiation point, but the point that would maximize the probability of finding a u-shaped relationship. Table S13 presents the linear regression results for low-income individuals and Table S14 presents the results for high-income individuals. As in our previous analyses, controlling for age, gender or country of residence does not significantly affect our results. These coefficients are estimated without including the individuals with a cut-off income in the low or high-income samples. Including these individuals to either the low-income group or the high-income group does not change our results. All reported coefficients are standardized. 
Table S13: OLS estimates for low-income individuals.

\begin{tabular}{|c|c|c|c|c|c|c|}
\hline & \multicolumn{6}{|c|}{ Dependent variable: } \\
\hline & Average & SD & Rel.SD & RMSSD & TKEO & PAC \\
\hline & $(1)$ & $(2)$ & $(3)$ & $(4)$ & $(5)$ & $(6)$ \\
\hline Income & $\begin{array}{c}0.063^{* * *} \\
(0.009)\end{array}$ & $\begin{array}{c}-0.116^{* * *} \\
(0.008)\end{array}$ & $\begin{array}{c}-0.091^{* * *} \\
(0.008)\end{array}$ & $\begin{array}{c}-0.109^{* * *} \\
(0.008)\end{array}$ & $\begin{array}{c}-0.101^{* * *} \\
(0.008)\end{array}$ & $\begin{array}{c}-0.101^{* * *} \\
(0.008)\end{array}$ \\
\hline Constant & $\begin{array}{c}0.000 \\
(0.009)\end{array}$ & $\begin{array}{c}0.000 \\
(0.008)\end{array}$ & $\begin{array}{c}0.000 \\
(0.008)\end{array}$ & $\begin{array}{c}0.000 \\
(0.008)\end{array}$ & $\begin{array}{c}0.000 \\
(0.008)\end{array}$ & $\begin{array}{c}0.000 \\
(0.008)\end{array}$ \\
\hline Observations & 12,600 & 13,768 & 13,768 & 13,768 & 13,768 & 13,768 \\
\hline $\mathrm{R}^{2}$ & 0.004 & 0.013 & 0.008 & 0.012 & 0.010 & 0.010 \\
\hline Adjusted $\mathrm{R}^{2}$ & 0.004 & 0.013 & 0.008 & 0.012 & 0.010 & 0.010 \\
\hline Residual Std. Error & 0.998 & 0.993 & 0.996 & 0.994 & 0.995 & 0.995 \\
\hline F Statistic & $50.300^{* * *}$ & $186.148^{* * *}$ & $115.387^{* * *}$ & $166.222^{* * *}$ & $140.913^{* * *}$ & $140.809^{* * *}$ \\
\hline
\end{tabular}

Table S14: OLS estimates for high-income individuals.

\begin{tabular}{|c|c|c|c|c|c|c|}
\hline & \multicolumn{6}{|c|}{ Dependent variable: } \\
\hline & $\begin{array}{c}\text { Average } \\
(1)\end{array}$ & $\begin{array}{l}\mathrm{SD} \\
(2)\end{array}$ & $\begin{array}{c}\text { Rel.SD } \\
(3)\end{array}$ & $\begin{array}{c}\text { RMSSD } \\
(4)\end{array}$ & $\begin{array}{c}\text { TKEO } \\
(5)\end{array}$ & $\begin{array}{c}\text { PAC } \\
(6) \\
\end{array}$ \\
\hline Income & $\begin{array}{c}0.027 \\
(0.017)\end{array}$ & $\begin{array}{l}-0.003 \\
(0.021)\end{array}$ & $\begin{array}{c}0.005 \\
(0.021)\end{array}$ & $\begin{array}{l}-0.028 \\
(0.021)\end{array}$ & $\begin{array}{l}-0.008 \\
(0.021)\end{array}$ & $\begin{array}{r}-0.036^{*} \\
(0.021)\end{array}$ \\
\hline Constant & $\begin{array}{c}0.000 \\
(0.017)\end{array}$ & $\begin{array}{l}-0.000 \\
(0.021)\end{array}$ & $\begin{array}{c}-0.000 \\
(0.021)\end{array}$ & $\begin{array}{c}0.000 \\
(0.021)\end{array}$ & $\begin{array}{l}-0.000 \\
(0.021)\end{array}$ & $\begin{array}{l}-0.000 \\
(0.021)\end{array}$ \\
\hline Observations & 3,510 & 2,174 & 2,174 & 2,174 & 2,174 & 2,174 \\
\hline $\mathrm{R}^{2}$ & 0.001 & 0.00001 & 0.00003 & 0.001 & 0.0001 & 0.001 \\
\hline Adjusted $\mathrm{R}^{2}$ & 0.0005 & -0.0005 & -0.0004 & 0.0003 & -0.0004 & 0.001 \\
\hline Residual Std. Error & 1.000 & 1.000 & 1.000 & 1.000 & 1.000 & 1.000 \\
\hline F Statistic & 2.594 & 0.016 & 0.060 & 1.754 & 0.153 & $2.857^{*}$ \\
\hline
\end{tabular}



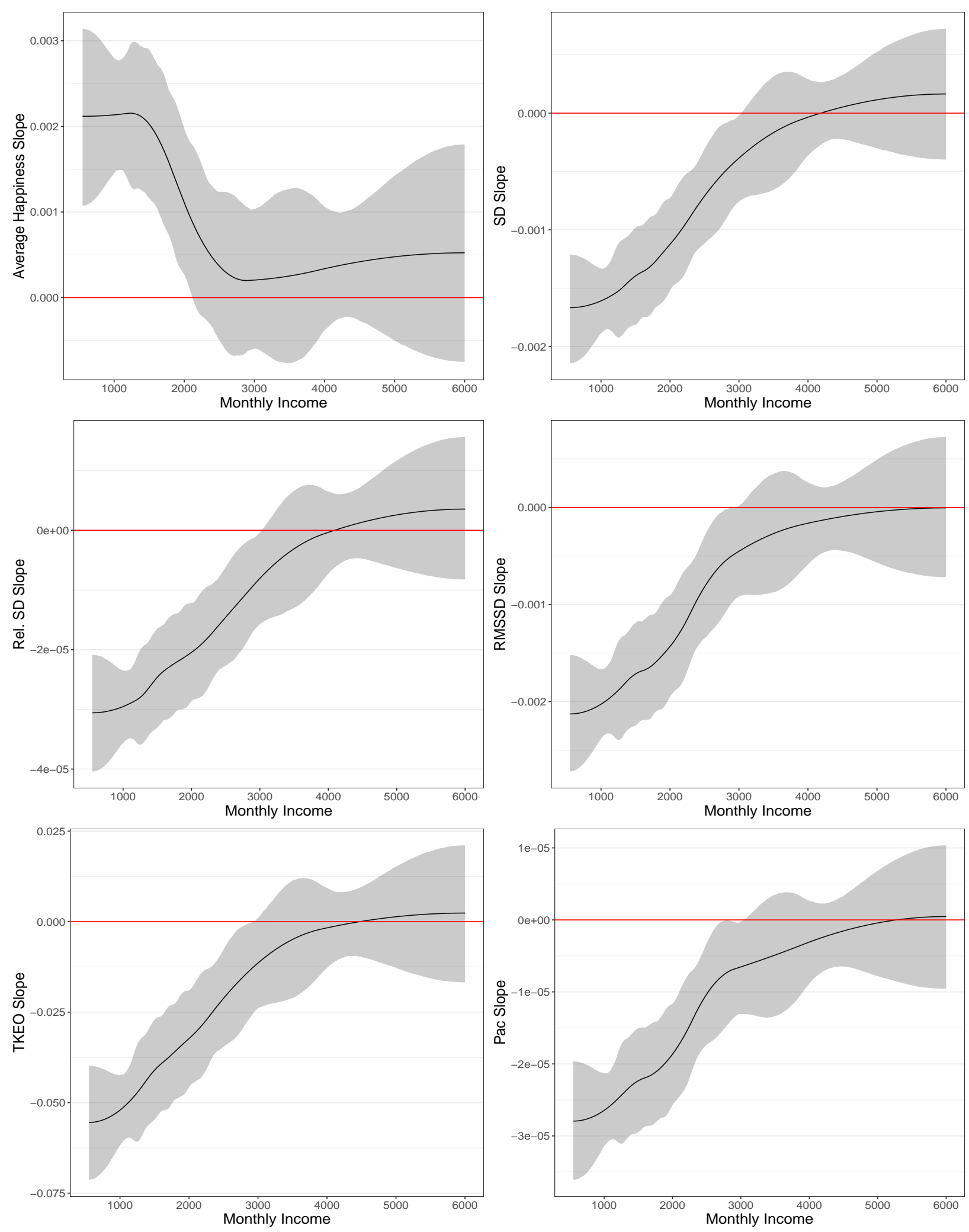

Figure S2: Splines' derivatives with 95\% C.I. (in gray). 


\section{Note 4: Specification Curves}

We run two separate specification curves for average happiness and happiness volatility. We start by looking at average happiness and consider the following specification choices:

- Income: We considered income either as an ordered categorical variable (i.e, income category) or a numeric variable (i.e, Euros per month). When income is numeric, we regressed average happiness on the logarithm of income.

- Missing: Treatment given to missing values. We either removed the data from individuals with missing observations, imputed the missing observations by Random Forest (RF) or imputed the missing observations by means of a Hot-Deck Algorithm (HD).

- Lowest: We considered specifications that included the lowest income group (individuals reporting an income of zero) and specifications that excluded them from the analyses. Given our logarithmic relationship between income and happiness, we only included this group in specifications considering income as an ordered categorical variable.

- Highest: We considered specifications that included the highest income group (individuals reporting an income of over 7500 euros per month) and specifications that excluded them from the analyses. If included and income is numeric, we assume that the middle point of the interval would be 9000 euros per month.

- Controls: We included specifications including and excluding demographic control variables (age, gender and country of residence).

In total we considered 36 specifications. Figure S3 presents the specification curve results. The coefficient of income is statistically significant (at the $95 \%$ confidence level) for all specifications. The effect of income on average happiness is larger for specifications using income as a numeric variable and without imputed data. We also see that excluding observations that reported an income of zero lead to larger coefficient sizes. As argued by 
Kahneman and Deaton, 2010, zero-income reports suffer from important reliability issues. Unsurprisingly, the effect of income on average happiness was jointly significant across all specifications $(p<0.002$ for each of the three significance criteria outlined in Simonsohn et al. (2020)).

Our second specification curve (Figure S4) analyzes the robustness of the relationship between happiness volatility and income. In addition to the previous analytical choices, we consider 5 different dependent variables (see Table S6), yielding a total of 180 specifications. Of these 180 specifications, income was significantly related to happiness fluctuations in 167 specifications. In all specifications, the coefficient of income was negative. The 13 specifications displaying a non-significant relationship between income and happiness volatility were estimated with data imputed by the Hot-Deck algorithm. Again, the effect of income on happiness fluctuations was jointly significant across all specifications $(p<0.002$ for each of the three significance criteria outlined in Simonsohn et al. (2020)). 

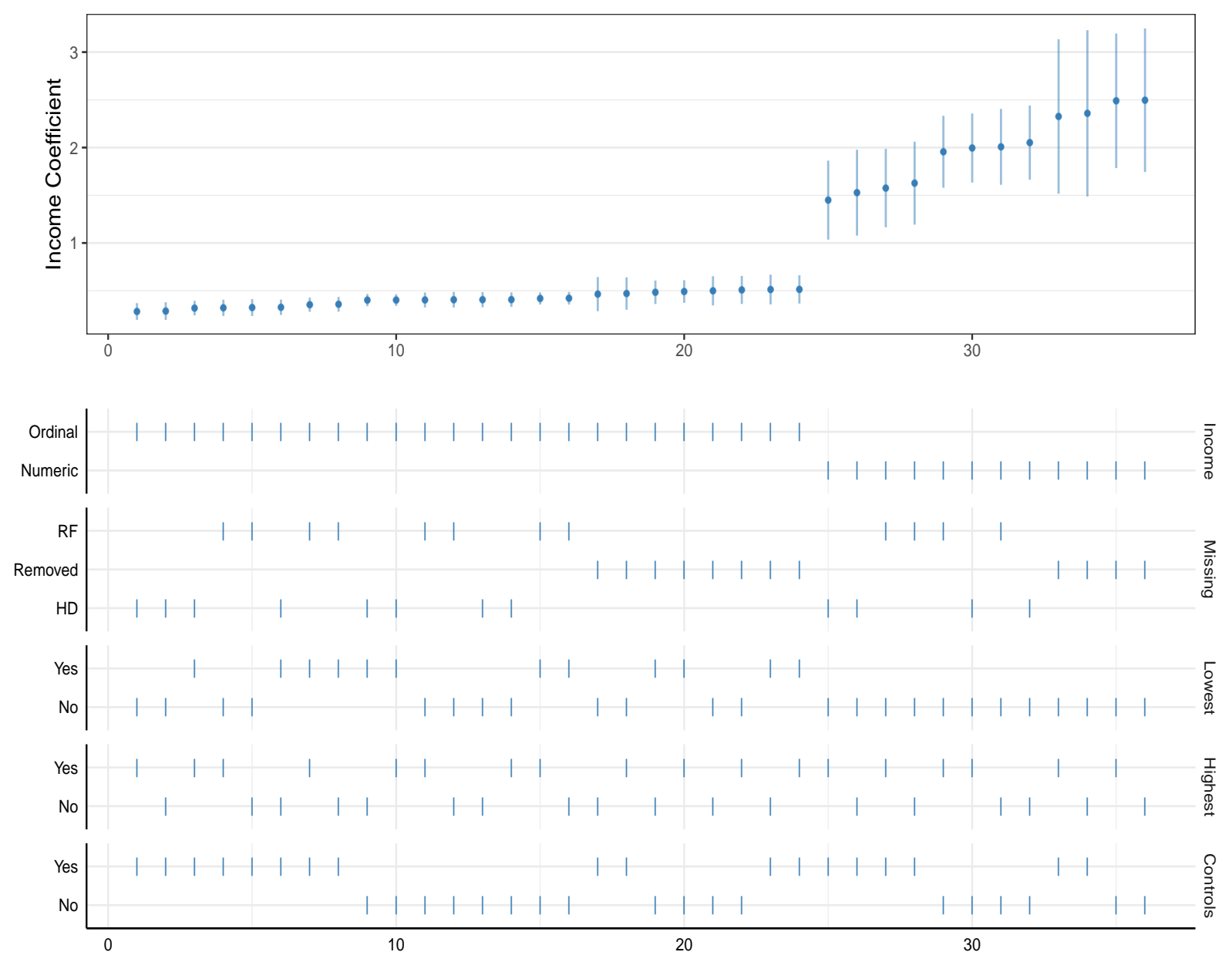

Figure S3: Specification curve 1 - income and average happiness. 

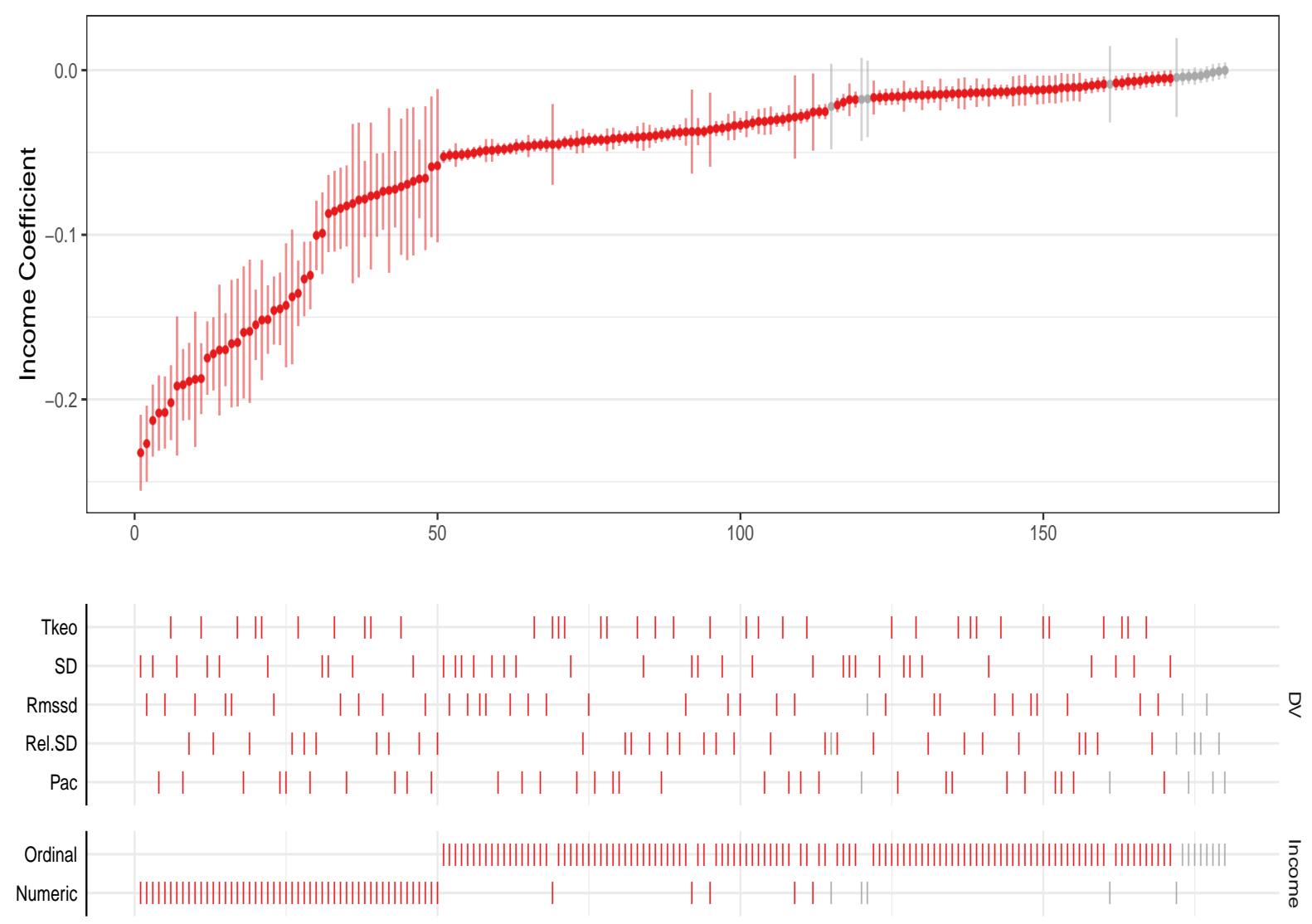

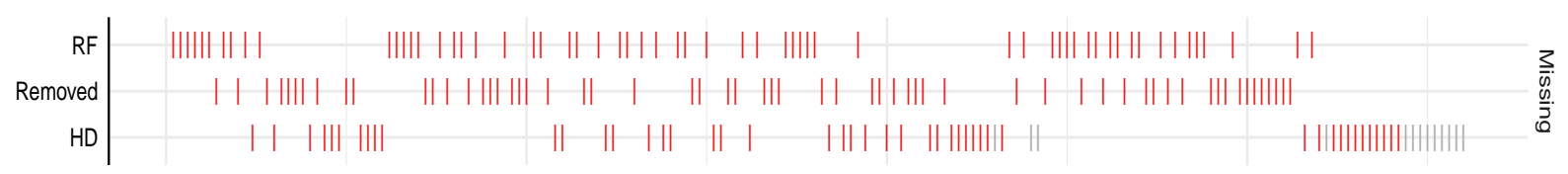

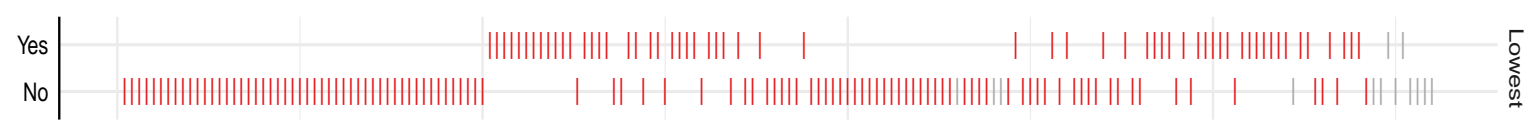

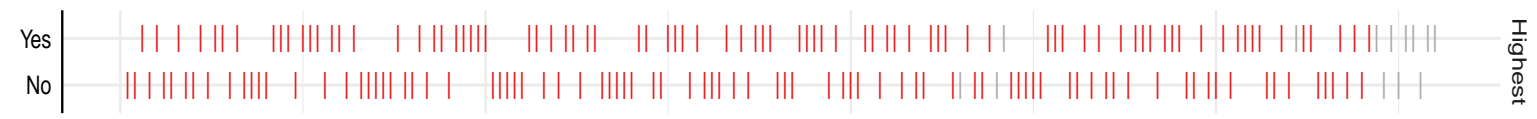

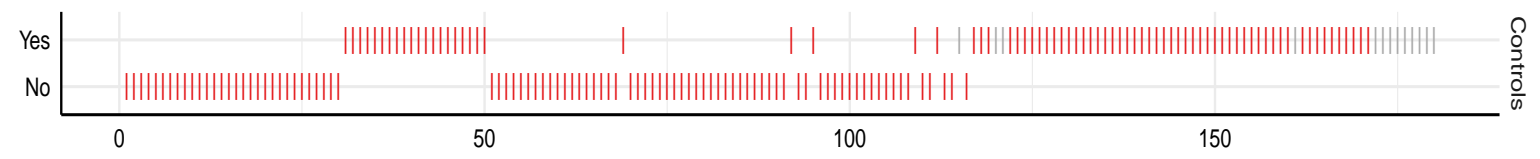

Figure S4: Specification curve 2 - income and happiness volatility. 


\section{Note 5: World Health Organization (WHO SAGE) Data and Re- sults}

\section{Participants and Day Reconstruction Method}

In the World Health Organization Study on Global Ageing and Adult Health (WHO SAGE), nationally representative samples of people in China, Ghana, India, Mexico, Russia, and South Africa completed a modified version of the Day Reconstruction Method - see AyusoMateos et al., 2013; Kowal et al., 2012 for detailed descriptions of the study. Participants were asked to report, in chronological order, what they did and how they felt across different episodes of their previous day. As most operationalizations of happiness volatility require at least three measurements, we excluded from our analyses participants who provided less than three episodes. Hence, our final sample consists of 25,634 participants.

\section{Happiness}

For each episode, respondents were asked to rate the extent to which they felt 7 emotions on a scale from 1 ("Not at all") and 3 ("Very much"). We then calculated a total composite happiness score by subtracting the mean of the negative emotions (worried, rushed, irritated or angry, depressed, tense or stressed) from the mean of the positive emotions (calm or relaxed, enjoying), resulting in a continuous score from -2 to 2 - see Taquet et al., 2020 for a similar approach.

\section{Income and demographics}

The WHO SAGE study measures income from the household ownership of durable goods, access to services, and housing characteristics - an approach that provides more reliable estimates of income than direct self-report questions in developing countries Ferguson et al., 2003. Each respondent provides information on a country-specific list of 21 items (durable goods, services, and housing characteristics; e.g., "do you own a refrigerator?"). Then, house- 
holds are arranged in an "asset ladder" using an item random-effects model and Bayesian post estimation. We use this continuous "asset ladder" variable as a measure of income (see WHO SAGE documentation). This dataset also contains information on the respondents' age and gender.

\section{Results}

Using the WHO data we can show that the relationship between income and happiness volatility is not unique to Western industrialized and rich societies. Income in this dataset is not self-reported but estimated from the respondents' ownership of durable goods, housing characteristics and access to services (see Ferguson et al. (2003) for a complete description of the estimation of income based on these variables). As the income ladders are country specific, we control for the participants' country of residence in all the presented specifications. We abstain from estimating country-level random effects due to the small number of countries presented in our dataset.

Employing non-linear methods (GAMs), we show that income significantly predicts happiness fluctuations (Table S15), even when controlling for demographic information (Table S16) and average happiness (Table S17). To provide the reader with a more intuitive presentation of our results, we repeat these analyses using linear regressions (Table S18-S20). As in our previous results, the reported regression coefficients are standardized for all numeric variables (income, age). We control for country of residence in all our analyses (coefficients not reported for brevity). 
Table S15: WHO SAGE data - GAM results.

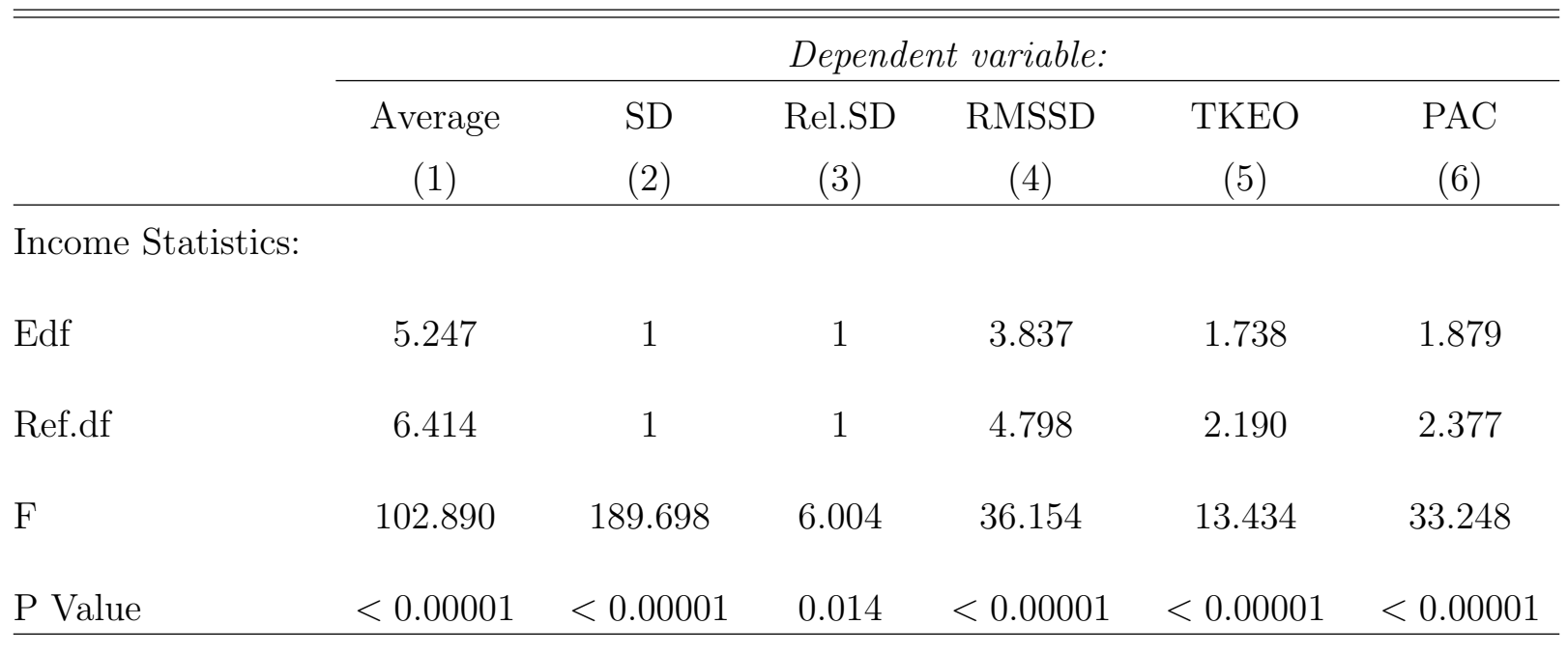

Table S16: WHO SAGE data - GAM results (controlling for age and gender).

\begin{tabular}{lcccccc}
\hline \hline & \multicolumn{5}{c}{ Dependent variable: } \\
\cline { 2 - 6 } & Average & SD & Rel.SD & RMSSD & TKEO & PAC \\
& $(1)$ & $(2)$ & $(3)$ & $(4)$ & $(5)$ & $(6)$ \\
\hline Income Statistics: & & & & & & \\
Edf & 5.258 & 1 & 1 & 3.745 & 1 & 1 \\
Ref.df & 6.427 & 1 & 1 & 4.689 & 1 & 1 \\
F & 104.868 & 207.884 & 9.236 & 40.792 & 32.481 & 87.059 \\
P Value & $<0.00001$ & $<0.00001$ & 0.002 & $<0.00001$ & $<0.00001$ & $<0.00001$ \\
\hline
\end{tabular}


Table S17: WHO SAGE data - GAM results (controlling for age, gender and average happiness).

\begin{tabular}{lcccccc}
\hline \hline & \multicolumn{6}{c}{ Dependent variable: } \\
\cline { 2 - 7 } & Average & $\mathrm{SD}$ & Rel.SD & RMSSD & TKEO & PAC \\
& $(1)$ & $(2)$ & $(3)$ & $(4)$ & $(5)$ & $(6)$ \\
\hline Income Statistics: & & & & & & \\
Edf & - & 3.819 & 2.464 & 2.996 & 2.340 & 2.554 \\
Ref.df & - & 4.778 & 3.118 & 3.779 & 2.964 & 3.231 \\
F & - & 9.954 & 8.268 & 8.088 & 2.727 & 4.580 \\
P Value & - & $<0.00001$ & 0.00001 & 0.00001 & 0.046 & 0.003 \\
\hline
\end{tabular}

Table S18: WHO SAGE data - Linear regression results.

\begin{tabular}{lcccccc}
\hline \hline & \multicolumn{5}{c}{ Dependent variable: } \\
\cline { 2 - 6 } & Average & $\mathrm{SD}$ & Rel.SD & RMSSD & TKEO & PAC \\
& $(1)$ & $(2)$ & $(3)$ & $(4)$ & $(5)$ & $(6)$ \\
\hline Income & $0.173^{* * *}$ & $-0.100^{* * *}$ & $-0.018^{* *}$ & $-0.095^{* * *}$ & $-0.040^{* * *}$ & $-0.065^{* * *}$ \\
& $(0.007)$ & $(0.007)$ & $(0.007)$ & $(0.007)$ & $(0.007)$ & $(0.007)$ \\
& & & & & \\
Constant & $0.204^{* * *}$ & $-0.317^{* * *}$ & $-0.230^{* * *}$ & $-0.298^{* * *}$ & $-0.135^{* * *}$ & $-0.217^{* * *}$ \\
& $(0.011)$ & $(0.011)$ & $(0.011)$ & $(0.011)$ & $(0.011)$ & $(0.011)$ \\
& & & & & & 25,634 \\
Observations & 25,634 & 25,634 & 25,634 & 25,634 & 25,634 & 0.037 \\
$\mathrm{R}^{2}$ & 0.134 & 0.072 & 0.035 & 0.069 & 0.014 & 0.037 \\
Adjusted R & 0.134 & 0.072 & 0.035 & 0.069 & 0.014 & 0.982 \\
Residual Std. Error & 0.931 & 0.963 & 0.982 & 0.965 & 0.993 \\
F Statistic & $662.199^{* * *}$ & $331.160^{* * *}$ & $156.584^{* * *}$ & $316.401^{* * *}$ & $62.016^{* * *}$ & $165.859^{* * *}$ \\
\hline \hline Note: & \multicolumn{5}{c}{${ }^{*} \mathrm{p}<0.1 ;{ }^{* *} \mathrm{p}<0.05 ;{ }^{* * *} \mathrm{p}<0.01$}
\end{tabular}


Table S19: WHO SAGE data - Linear regression results (controlling for age and gender).

\begin{tabular}{|c|c|c|c|c|c|c|}
\hline & \multicolumn{6}{|c|}{ Dependent variable: } \\
\hline & Average & $\mathrm{SD}$ & Rel.SD & RMSSD & TKEO & $\mathrm{PAC}$ \\
\hline & $(1)$ & $(2)$ & $(3)$ & $(4)$ & $(5)$ & (6) \\
\hline Income & $\begin{array}{c}0.172^{* * *} \\
(0.007)\end{array}$ & $\begin{array}{c}-0.103^{* * *} \\
(0.007)\end{array}$ & $\begin{array}{c}-0.021^{* * *} \\
(0.007)\end{array}$ & $\begin{array}{c}-0.098^{* * *} \\
(0.007)\end{array}$ & $\begin{array}{c}-0.042^{* * *} \\
(0.008)\end{array}$ & $\begin{array}{c}-0.068^{* * *} \\
(0.007)\end{array}$ \\
\hline Age & $\begin{array}{l}0.016^{* *} \\
(0.006)\end{array}$ & $\begin{array}{c}-0.045^{* * *} \\
(0.006)\end{array}$ & $\begin{array}{c}-0.035^{* * *} \\
(0.007)\end{array}$ & $\begin{array}{c}-0.042^{* * *} \\
(0.006)\end{array}$ & $\begin{array}{c}-0.039^{* * *} \\
(0.007)\end{array}$ & $\begin{array}{c}-0.040^{* * *} \\
(0.007)\end{array}$ \\
\hline Male & $\begin{array}{c}0.070^{* * *} \\
(0.012)\end{array}$ & $\begin{array}{c}-0.029^{* *} \\
(0.012)\end{array}$ & $\begin{array}{l}0.022^{*} \\
(0.013)\end{array}$ & $\begin{array}{c}-0.022^{*} \\
(0.012)\end{array}$ & $\begin{array}{l}-0.020 \\
(0.013)\end{array}$ & $\begin{array}{l}-0.018 \\
(0.013)\end{array}$ \\
\hline Constant & $\begin{array}{c}0.166^{* * *} \\
(0.012)\end{array}$ & $\begin{array}{c}-0.293^{* * *} \\
(0.012)\end{array}$ & $\begin{array}{c}-0.234^{* * *} \\
(0.013)\end{array}$ & $\begin{array}{c}-0.278^{* * *} \\
(0.013)\end{array}$ & $\begin{array}{c}-0.117^{* * *} \\
(0.013)\end{array}$ & $\begin{array}{c}-0.200^{* * *} \\
(0.013)\end{array}$ \\
\hline Observations & 25,594 & 25,594 & 25,594 & 25,594 & 25,594 & 25,594 \\
\hline $\mathrm{R}^{2}$ & 0.136 & 0.074 & 0.036 & 0.071 & 0.016 & 0.039 \\
\hline Adjusted $\mathrm{R}^{2}$ & 0.135 & 0.074 & 0.036 & 0.070 & 0.015 & 0.039 \\
\hline Residual Std. Error & 0.930 & 0.962 & 0.982 & 0.964 & 0.993 & 0.982 \\
\hline F Statistic & $502.328^{* * *}$ & $255.387^{* * *}$ & $120.607^{* * *}$ & $242.757^{* * *}$ & $51.366^{* * *}$ & $129.460^{* * *}$ \\
\hline
\end{tabular}


Table S20: WHO SAGE data - Linear regression results (controlling for age, gender and average happiness).

\begin{tabular}{|c|c|c|c|c|c|c|}
\hline & \multicolumn{6}{|c|}{ Dependent variable: } \\
\hline & Average & $\mathrm{SD}$ & Rel.SD & RMSSD & TKEO & $\mathrm{PAC}$ \\
\hline & $(1)$ & $(2)$ & $(3)$ & $(4)$ & $(5)$ & $(6)$ \\
\hline Income & $\begin{array}{c}0.172^{* * *} \\
(0.007)\end{array}$ & $\begin{array}{c}-0.040^{* * *} \\
(0.007)\end{array}$ & $\begin{array}{c}-0.038^{* * *} \\
(0.007)\end{array}$ & $\begin{array}{c}-0.038^{* * *} \\
(0.007)\end{array}$ & $\begin{array}{c}-0.014^{*} \\
(0.008)\end{array}$ & $\begin{array}{c}-0.023^{* * *} \\
(0.007)\end{array}$ \\
\hline Average Happiness & & $\begin{array}{c}-0.363^{* * *} \\
(0.006)\end{array}$ & $\begin{array}{c}0.100^{* * *} \\
(0.007)\end{array}$ & $\begin{array}{c}-0.347^{* * *} \\
(0.006)\end{array}$ & $\begin{array}{c}-0.161^{* * *} \\
(0.007)\end{array}$ & $\begin{array}{c}-0.257^{* * *} \\
(0.006)\end{array}$ \\
\hline Age & $\begin{array}{l}0.016^{* *} \\
(0.006)\end{array}$ & $\begin{array}{c}-0.039^{* * *} \\
(0.006)\end{array}$ & $\begin{array}{c}-0.036^{* * *} \\
(0.007)\end{array}$ & $\begin{array}{c}-0.036^{* * *} \\
(0.006)\end{array}$ & $\begin{array}{c}-0.036^{* * *} \\
(0.007)\end{array}$ & $\begin{array}{c}-0.036^{* * *} \\
(0.006)\end{array}$ \\
\hline Male & $\begin{array}{c}0.070^{* * *} \\
(0.012)\end{array}$ & $\begin{array}{l}-0.004 \\
(0.012)\end{array}$ & $\begin{array}{c}0.015 \\
(0.013)\end{array}$ & $\begin{array}{c}0.002 \\
(0.012)\end{array}$ & $\begin{array}{l}-0.009 \\
(0.013)\end{array}$ & $\begin{array}{l}-0.001 \\
(0.012)\end{array}$ \\
\hline Constant & $\begin{array}{c}0.166^{* * *} \\
(0.012)\end{array}$ & $\begin{array}{c}-0.233^{* * *} \\
(0.012)\end{array}$ & $\begin{array}{c}-0.250^{* * *} \\
(0.013)\end{array}$ & $\begin{array}{c}-0.221^{* * *} \\
(0.012)\end{array}$ & $\begin{array}{c}-0.091^{* * *} \\
(0.013)\end{array}$ & $\begin{array}{c}-0.158^{* * *} \\
(0.012)\end{array}$ \\
\hline Observations & 25,594 & 25,594 & 25,594 & 25,594 & 25,594 & 25,594 \\
\hline $\mathrm{R}^{2}$ & 0.136 & 0.188 & 0.045 & 0.175 & 0.038 & 0.096 \\
\hline Adjusted $\mathrm{R}^{2}$ & 0.135 & 0.188 & 0.045 & 0.175 & 0.038 & 0.095 \\
\hline Residual Std. Error & 0.930 & 0.901 & 0.977 & 0.909 & 0.982 & 0.952 \\
\hline F Statistic & $502.328^{* * *}$ & $657.993^{* * *}$ & $133.954^{* * *}$ & $602.233^{* * *}$ & $112.931^{* * *}$ & $300.843^{* * *}$ \\
\hline
\end{tabular}




\section{Note 6: Point and Collective Anomalies}

To jointly identify anomalous happiness moments and sequences, we used a Collective and Point Anomaly Detection (CAPA, Fisch et al., 2019) machine learning algorithm. Figure S5 exemplifies the results of this procedure for 3 participants in our "58 seconds" dataset. We restricted our analyses to individuals with a MAD (Mean Absolute Deviation) in happiness larger than 0 (as the CAPA procedure relies on a robust normalization that requires a positive MAD). The final sample consisted of 5002 participants and a minimum of 50 happiness observations per participant.

\section{Anomalous moments}

Table S21 presents the results of the frequency analyses. To compute the frequency with which an individual experiences anomalous happiness reports, we estimated the proportion of an individuals' happiness reports that were identified as anomalous momentary reports. All numeric variables are standardized before estimating the regression. To avoid potential confounds, we control for age, gender and country of residence (coefficients not reported for brevity) in all our subsequent analyses. To ensure that our results were not driven by individuals with extremely high or low average happiness, we dropped from our our analyses of anomalous moments those individuals with an average happiness of over 90 or below 10. This resulted in dropping approximately $2 \%$ of the individuals in our sample. Table S22 presents the estimated OLS coefficients of income on the happiness levels of positive (above and individual's average happiness) and negative (below average) anomalous

happiness observations. All models include clustered standard error at the individual level. All numeric variables are standardized before estimating the regression. 
Table S21: Frequency of negative and positive anomalous moments of happiness. The coefficients of numeric variables are standardized.

\begin{tabular}{lcc}
\hline \hline & \multicolumn{2}{c}{ Dependent variable: } \\
\cline { 2 - 3 } & Frequency (Neg.) & Frequency (Pos.) \\
\hline Log Income & 0.006 & -0.005 \\
& $(0.016)$ & $(0.016)$ \\
Age & 0.004 & -0.004 \\
& $(0.015)$ & $(0.015)$ \\
Male & & -0.015 \\
& 0.031 & $(0.032)$ \\
Constant & $(0.032)$ & -0.035 \\
& & $(0.224)$ \\
& 0.147 & 4,896 \\
Observations & $(0.224)$ & 0.0003 \\
$\mathrm{R}^{2}$ & & -0.001 \\
Adjusted ${ }^{2}$ & 4,896 & 1.000 \\
Residual Std. Error & 0.001 & 0.189 \\
F Statistic & -0.001 & $\mathrm{p}<0.1 ;{ }^{* *} \mathrm{p}<0.05 ;{ }^{* * *} \mathrm{p}<0.01$ \\
\hline \hline Note: & 1.000 &
\end{tabular}


Table S22: Happiness of negative and positive anomalous moments. Coefficients of numeric variables are standardized. Standard errors are clustered at the participant level.

\begin{tabular}{lcc}
\hline \hline & \multicolumn{2}{c}{ Dependent variable: } \\
\cline { 2 - 3 } & Happiness (Neg.) & Happiness (Pos.) \\
& $0.121^{* * *}$ & -0.056 \\
Log Income & $(0.036)$ & $(0.096)$ \\
& & \\
Age & 0.007 & -0.177 \\
& $(0.037)$ & $(0.14)$ \\
Male & 0.084 & 0.064 \\
& $(0.086)$ & $(0.201)$ \\
Constant & $-0.857^{* * *}$ & $1.137^{* * *}$ \\
& $(0.222)$ & $(0.201)$ \\
\hline Observations & 1471 & 206 \\
$\mathrm{R}^{2}$ & 0.023 & 0.049 \\
Adjusted $\mathrm{R}^{2}$ & 0.019 & 0.019 \\
\hline \hline Note: & ${ }^{*} \mathrm{p}<0.1 ;{ }^{* *} \mathrm{p}<0.05 ;{ }^{* * *} \mathrm{p}<0.01$ \\
\hline
\end{tabular}



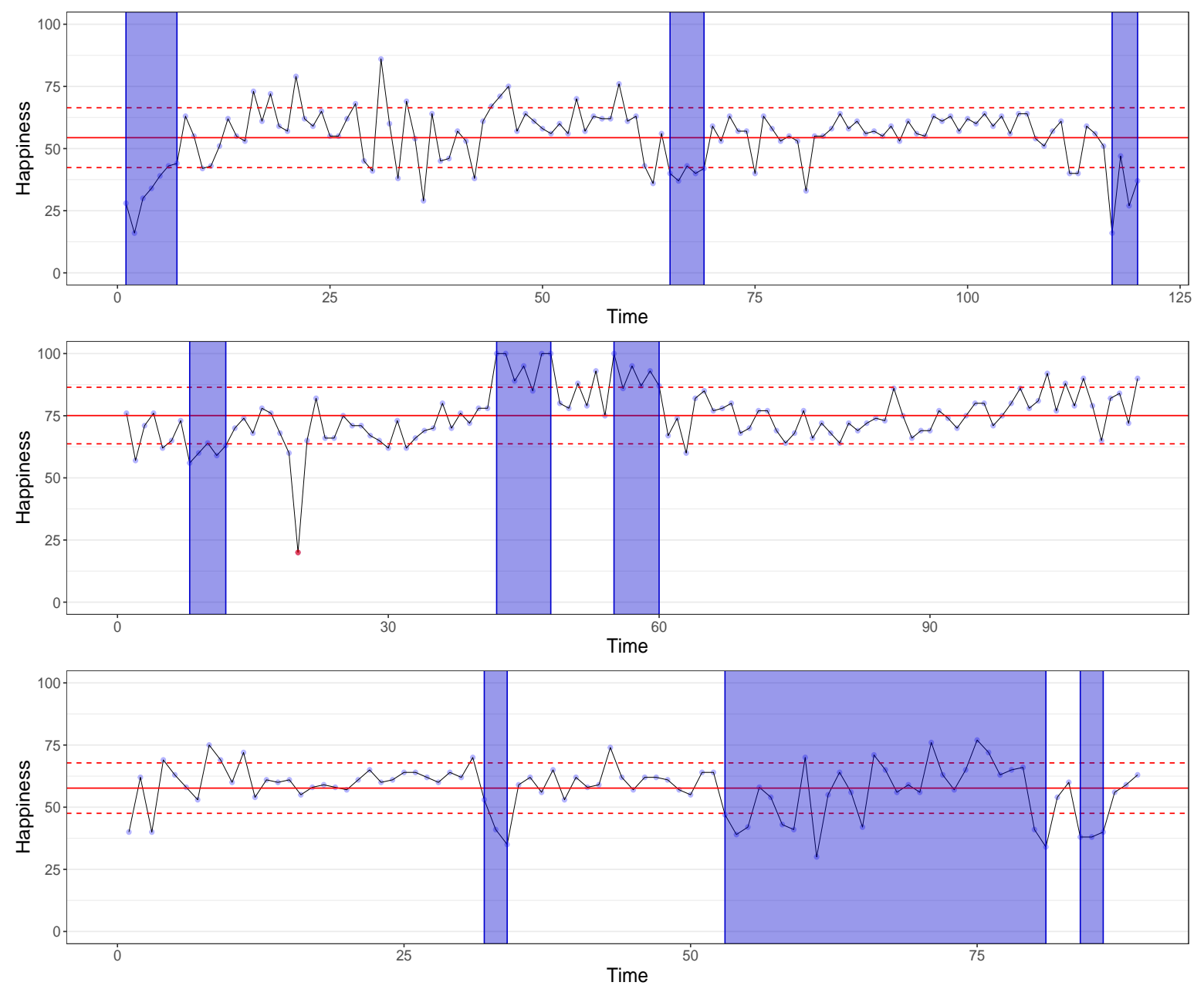

Figure S5: Results of PACA algorithm for 3 individuals. Intervals in blue represent anomalous periods of happiness. Points in red indicate anomalous moments of happiness. The horizontal solid line represents the individual's average happiness and the dotted lines the average happiness $+1 /-1$ standard deviation. 


\section{Anomalous Sequences:}

We categorized the anomalous periods experienced by the participants using a k-means clustering algorithm. Before performing the clustering algorithm, we centered the mean and SD in happiness of each sequence. In order to do so, we subtracted from a sequence's average and SD in happiness, the mean and SD across all observations of happiness of the individual experiencing the anomalous sequence. In doing so, our clustering procedure takes into account the sequence characteristics as compared to the typical mood of the individual experiencing it. We also standardized these centered variables to ensure the robustness of our procedure. Before running the clustering algorithm, we determined the optimal number of clusters using the average silhouette method. The silhouette method suggested an optimal partition consisting of 3 clusters (see Figure S6). Then, we performed the k-means algorithm and classified the sequences into three clusters. Figure S7 and Table S23 present the resulting clusters based on the centered variables and the summary statistics of the anomalous period of happiness contained in each cluster.

We included three metrics of interest as dependent variables in the following analyses. First, we considered the frequency of each type of anomalous period. We measured frequency as the number of anomalous sequences divided by an individual's total number of happiness reports. We measured a sequence intensity using its average happiness. Finally, we measured a sequence duration as its length (in number of happiness reports). Considering length in terms of actual time (hours) does not affect our results. Tables S24-S26 presents the results

of our analyses of frequency (Table S24), intensity (Table S25) and duration (Table S26) of anomalous happiness periods. All models control for country of residence (coefficients not reported for brevity). 
Table S23: Median duration, average happiness and standard deviation (SD) of happiness for each cluster of anomalous sequences. Average and SD in happiness are first estimated at the sequence level. Then the resulting mean happiness and happiness SD are averaged across sequences within each cluster.

\begin{tabular}{lccc}
\hline \hline & Average Happiness & Std. Deviation in Happiness & Median Duration (in hours) \\
\hline Cluster 1 & 52.876 & 16.055 & 116.38 \\
Cluster 2 & 84.356 & 2.410 & 50.46 \\
Cluster 3 & 34.468 & 4.266 & 47.15 \\
\hline
\end{tabular}

Table S24: Frequency of anomalous periods of increased volatility (Model 1), sustained happiness (Model 2) and sustained unhappiness (Model 3). Coefficients of numeric variables are standardized.

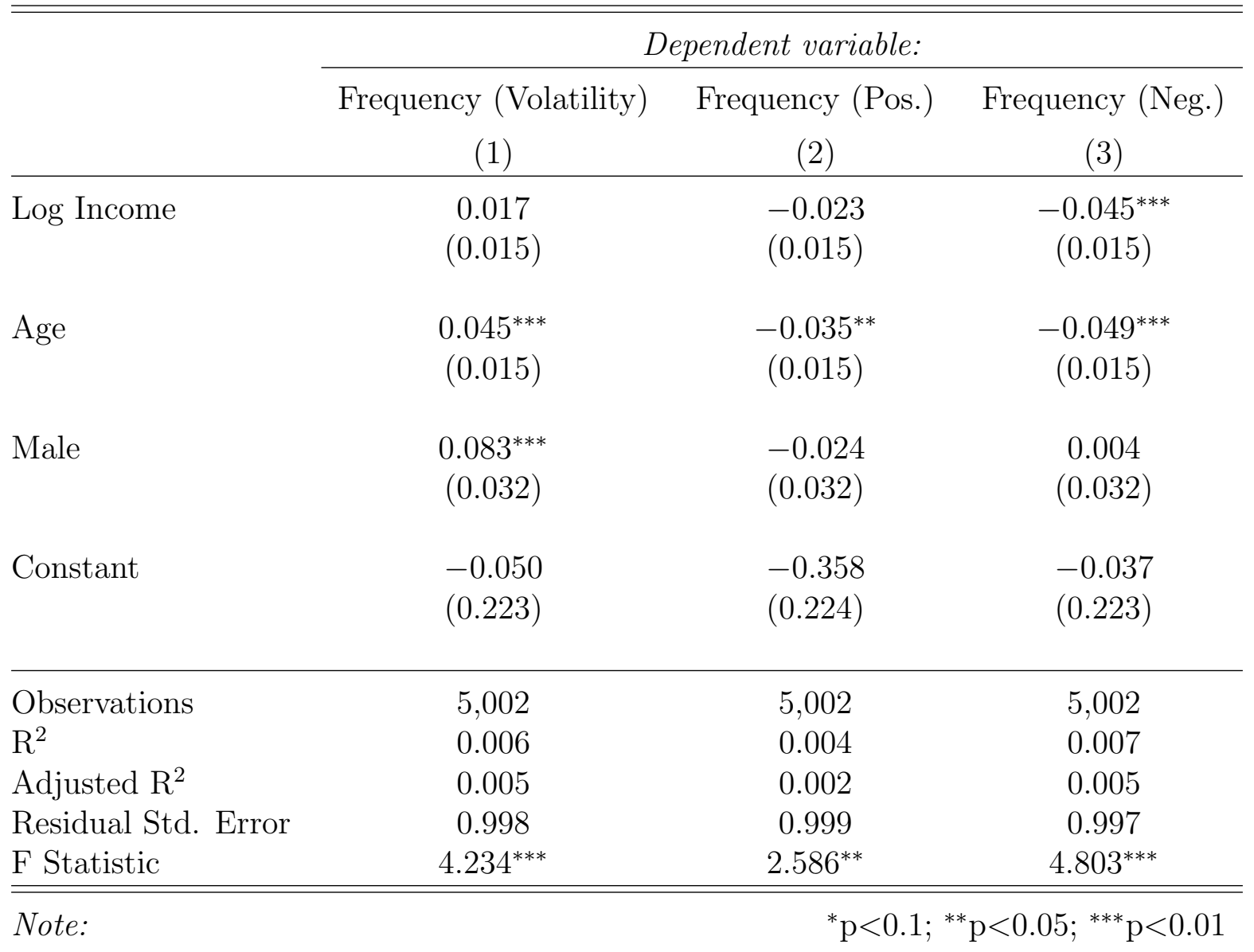


Table S25: Intensity (happiness) of anomalous periods of increased volatility (Model 1), sustained happiness (Model 2) and sustained unhappiness (Model 3). Coefficients of numeric variables are standardized. All standard errors are clustered at the participant level.

\begin{tabular}{lccc}
\hline \hline & \multicolumn{3}{c}{ Dependent variable: } \\
\cline { 2 - 4 } & Happiness (Volatility) & Happiness (Pos.) & Happiness (Neg.) \\
& $(1)$ & $(2)$ & $0.101^{* * *}$ \\
\hline Log Income & $(0.031$ & $(0.024)$ & $(0.028)$ \\
& & & \\
Age & 0.017 & $-0.05^{* *}$ & 0.021 \\
& $(0.024)$ & $(0.024)$ & $(0.029)$ \\
Male & $0.206^{* * *}$ & 0.06 & -0.076 \\
& $(0.052)$ & $(0.048)$ & $(0.063)$ \\
Constant & & & -0.294 \\
& $(0.046$ & $-0.685^{* * *}$ & $(0.383)$ \\
\hline Observations & & $(0.165)$ & 4,280 \\
$\mathrm{R}^{2}$ & 5,084 & & 0.013 \\
Adjusted $\mathrm{R}^{2}$ & 0.014 & 0.739 & 0.011 \\
\hline \hline Note: & 0.012 & 0.006 & ${ }^{*} \mathrm{p}<0.1 ;{ }^{* *} \mathrm{p}<0.05 ;{ }^{* * *} \mathrm{p}<0.01$ \\
\end{tabular}


Table S26: Duration of anomalous periods of increased volatility (Model 1), sustained happiness (Model 2) and sustained unhappiness (Model 3). Coefficients of numeric variables are standardized. All standard errors are clustered at the participant level.

\begin{tabular}{lccc}
\hline & \multicolumn{3}{c}{ Dependent variable: } \\
\cline { 2 - 4 } & $(1)$ & $(2)$ & $(3)$ \\
\hline Log Income & -0.015 & -0.009 & $0.022^{*}$ \\
& $(0.017)$ & $(0.013)$ & $(0.013)$ \\
Age & 0.010 & & \\
& $(0.015)$ & $0.082^{* * *}$ & 0.027 \\
& & $(0.018)$ & $(0.018)$ \\
Male & 0.014 & 0.001 & -0.001 \\
& $(0.035)$ & $(0.028)$ & $(0.036)$ \\
Constant & $-0.256^{* * *}$ & -0.104 & $-0.233^{* * *}$ \\
& $(0.039)$ & $(0.108)$ & $(0.045)$ \\
\hline Observations & 5,084 & & 4,280 \\
$\mathrm{R}^{2}$ & 0.001 & 8,739 & 0.003 \\
Adjusted $\mathrm{R}^{2}$ & -0.001 & 0.006 & 0.001 \\
\hline \hline Note: & & 0.005 & ${ }^{*} \mathrm{p}<0.1 ;{ }^{* *} \mathrm{p}<0.05 ;{ }^{* * *} \mathrm{p}<0.01$ \\
\end{tabular}




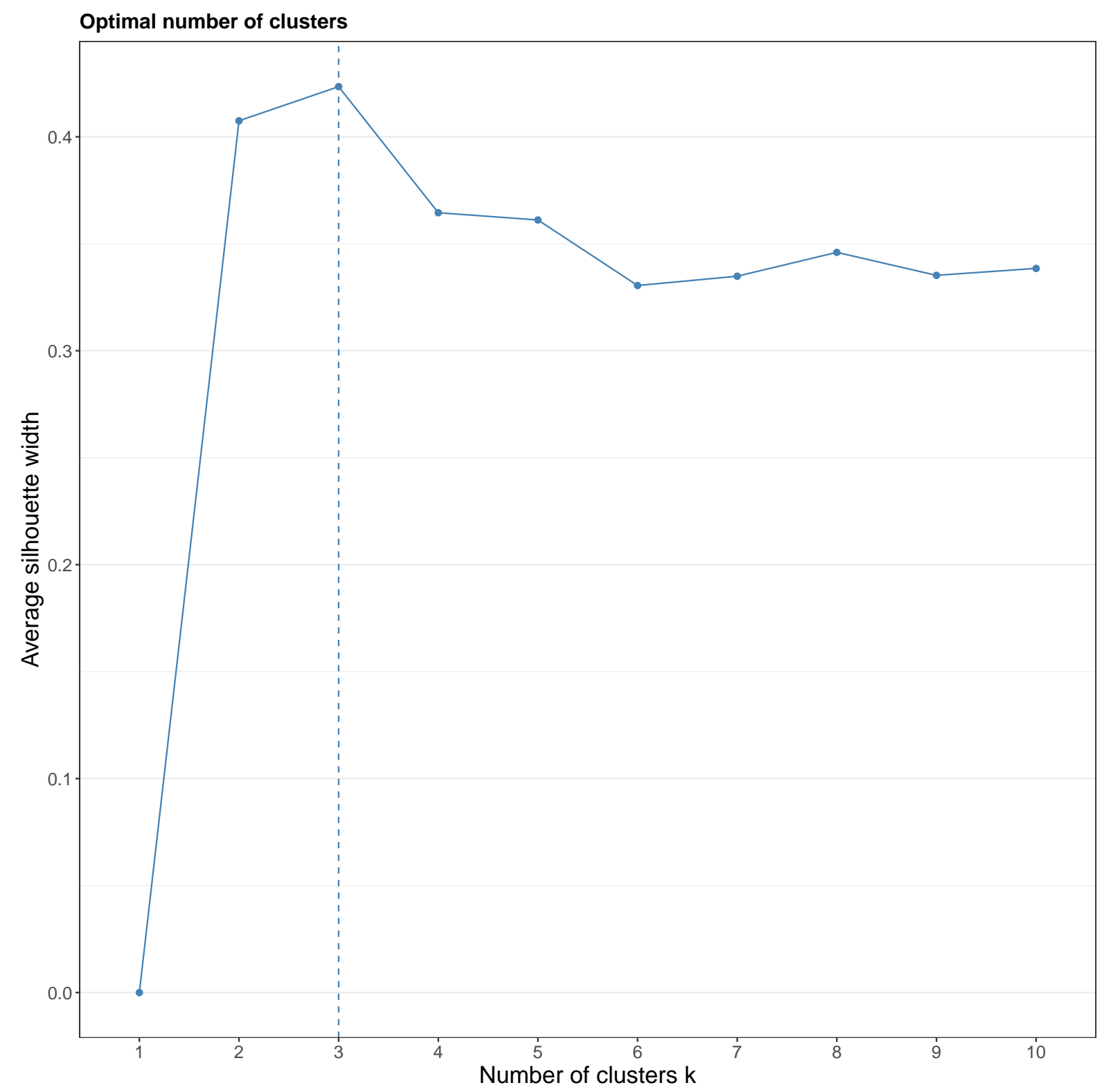

Figure S6: Optimal Number of clusters. 


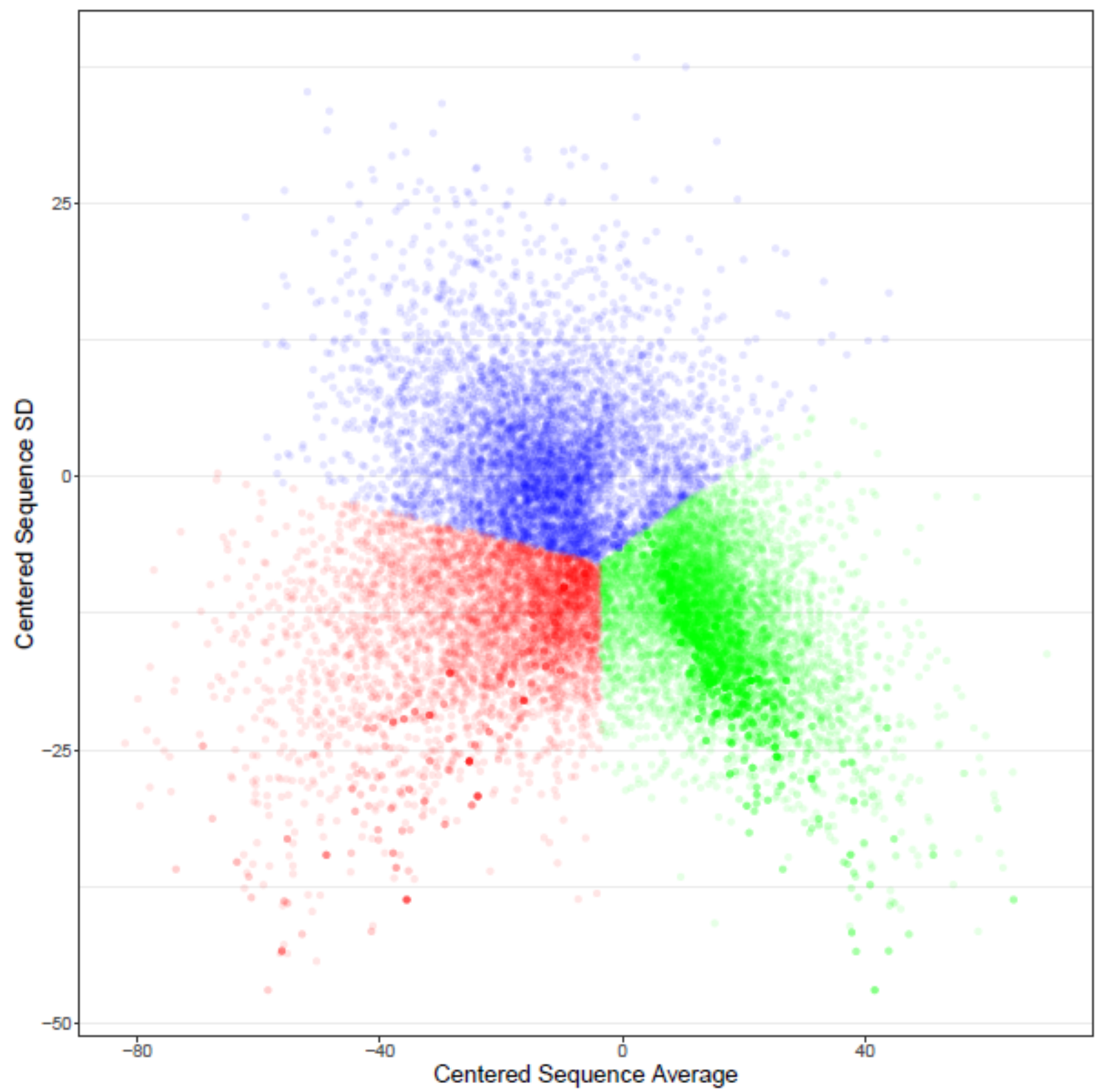

Figure S7: Clusters of anomalous sequences. Results of k-means clustering over our 18,103 anomalous sequences. Cluster 1 (blue) represents sequences with a higher emotional variability than an individual's typical variability. Cluster 2 (green) represents sequences that are on average happier than an individual typical mood. Cluster 3 (red) represents sequences that are lower on happiness than an individual's typical mood. 


\section{Note 7: Robustness of CAPA Results}

Results from the CAPA analyses are robust to alternative, more conventional, ways to identify extreme observations. In this section, we show that focusing on the bottom $1 \%, 5 \%$, and $10 \%$ of all happiness observations - either across individuals or within subjects - yields similar conclusions. In order to do so, we focus on our larger sample size of 17,278 individuals.

To ensure the robustness of our CAPA results, for each individual, we estimated the proportion of his or her happiness moments that fall within the bottom 1\%, $5 \%$, and $10 \%$ of all happiness observations across individuals. For those individuals that had at least 1 happiness report in the bottom $5 \%$ or $10 \%$ of all happiness observations across individuals, we also estimated the intensity (average happiness) of those extreme moments. We do not estimate the intensity of observations in the bottom $1 \%$ as these observations always take a value of 0 . Table S27 presents the results (OLS coefficients) of regressing the proportion of extreme happiness observations on the logarithm of income (controlling for demographic

characteristics). Table S28 presents the results of regressing the intensity (average happiness) of these extreme observations on income (controlling for demographic characteristics).

To further ensure the robustness of these results, we take a within-individual approach. For each participant in our sample, we estimated the intensity (average happiness) of the bottom 1\%, 5\%, and $10 \%$ of his or her happiness observations. Table S29 presents the results of regressing the intensity of these observation on income (controlling for demographic characteristics). For brevity, we don't report "country of residence" coefficients. 
Table S27: Proportion of observations per individual that belong to the bottom 1\%, 5\%, and $10 \%$ of all happiness observations across individuals. Coefficients of numeric variables are standardized.

\begin{tabular}{lccc}
\hline \hline & \multicolumn{3}{c}{ Dependent variable: } \\
\cline { 2 - 4 } & $(1)$ & $(2)$ & $(3)$ \\
\hline Proportion $1 \%$ & Proportion $5 \%$ & Proportion $10 \%$ \\
& $-0.046^{* * *}$ & $-0.049^{* * *}$ & $-0.059^{* * *}$ \\
Age & $(0.008)$ & $(0.008)$ & $(0.008)$ \\
& $-0.057^{* * *}$ & $-0.051^{* * *}$ & $-0.050^{* * *}$ \\
Male & $(0.008)$ & $(0.008)$ & $(0.008)$ \\
& & & $-0.072^{* * *}$ \\
Constant & -0.014 & $-0.054^{* * *}$ & $(0.016)$ \\
& $(0.016)$ & $(0.016)$ & 0.078 \\
& & & $(0.117)$ \\
\hline Observations & $0.264^{* *}$ & 0.135 & 17,278 \\
R $^{2}$ & $(0.118)$ & $(0.118)$ & 0.011 \\
Adjusted R & & & 0.010 \\
Residual Std. Error & 17,278 & 17,278 & 0.995 \\
F Statistic & 0.008 & 0.009 & $23.821^{* * *}$ \\
\hline \hline Note: & 0.008 & 0.008 & 0.996 \\
\hline
\end{tabular}


Table S28: Intensity (average happiness) of observations belonging to the bottom 5\% and $10 \%$ of all happiness observations across individuals. Coefficients of numeric variables are standardized.

\begin{tabular}{lcc}
\hline \hline & \multicolumn{2}{c}{ Dependent variable: } \\
\cline { 2 - 3 } & $(1)$ & $(2)$ \\
\hline Happiness (Obs. in 5\%) & Happiness (Obs. in 10\%) \\
& $0.026^{* *}$ & $0.040^{* * *}$ \\
& $(0.012)$ & $(0.010)$ \\
Age & $0.086^{* * *}$ & $0.085^{* * *}$ \\
& $(0.012)$ & $(0.010)$ \\
Male & & 0.016 \\
& $(0.025)$ & $(0.020)$ \\
Constant & -0.267 & -0.062 \\
& $(0.182)$ & $(0.144)$ \\
& & 11,671 \\
Observations & 7,941 & 0.012 \\
R $^{2}$ & 0.011 & 0.011 \\
Adjusted R & & 0.994 \\
Residual Std. Error & 0.010 & $17.449^{* * *}$ \\
F Statistic & 0.995 & ${ }^{*} \mathrm{p}<0.1 ;{ }^{* *} \mathrm{p}<0.05 ;{ }^{* * *} \mathrm{p}<0.01$ \\
\hline \hline Note: & $10.823^{* * *}$ &
\end{tabular}


Table S29: Intensity (average happiness) of observations belonging to the bottom 1\%, 5\% and $10 \%$ of happiness observations within individuals. Coefficients of numeric variables are standardized.

\begin{tabular}{lccc}
\hline \hline & \multicolumn{3}{c}{ Dependent variable: } \\
\cline { 2 - 4 } & $(1)$ & $(2)$ & $(3)$ \\
\hline Lappiness $(1 \%)$ & Happiness $(5 \%)$ & Happiness $(10 \%)$ \\
& $0.066^{* * *}$ & $0.072^{* * *}$ & $0.076^{* * *}$ \\
& $(0.008)$ & $(0.008)$ & $(0.008)$ \\
Age & $0.081^{* * *}$ & $0.111^{* * *}$ & $0.109^{* * *}$ \\
& $(0.008)$ & $(0.008)$ & $(0.008)$ \\
Male & & & $0.206^{* * *}$ \\
& $0.242^{* * *}$ & $0.212^{* * *}$ & $(0.016)$ \\
Constant & $(0.016)$ & $(0.016)$ & -0.136 \\
& & & $(0.116)$ \\
& -0.144 & -0.139 & 17,278 \\
Observations & $(0.116)$ & $(0.116)$ & 0.037 \\
$\mathrm{R}^{2}$ & & & 0.037 \\
Adjusted R & & 17,278 & 0.982 \\
Residual Std. Error & 0.985 & 0.037 & $83.107^{* * *}$ \\
F Statistic & $68.750^{* * *}$ & $83.600^{* * *}$ & ${ }^{*} \mathrm{p}<0.1 ;{ }^{* *} \mathrm{p}<0.05 ;{ }^{* * *} \mathrm{p}<0.01$ \\
\hline \hline Note: & & &
\end{tabular}




\section{Note 8: Temporal Variability of Anomalous Happiness Observa- tions and Periods}

In the main text (Figure 4) we presented the GAM Smooth function of the prevalence of anomalous happiness reports (happiness reports belonging to either an anomalous happiness moment or an anomalous happiness period) across the month. For completeness, Figure S8 presents a similar analysis focusing exclusively on anomalous negative observations (either anomalous negative moments or period of sustained unhappiness). For low-income individuals, anomalous negative observations are more common during the first week of the month (i.e., when facing large expenditures such as rent or loan repayments) and during the last few days of the month (i.e., when waiting for their monthly salary). For high income individuals, the opposite picture arises, suggesting that the relationship between income and the negative anomalous moments and periods of unhappiness is causal. 


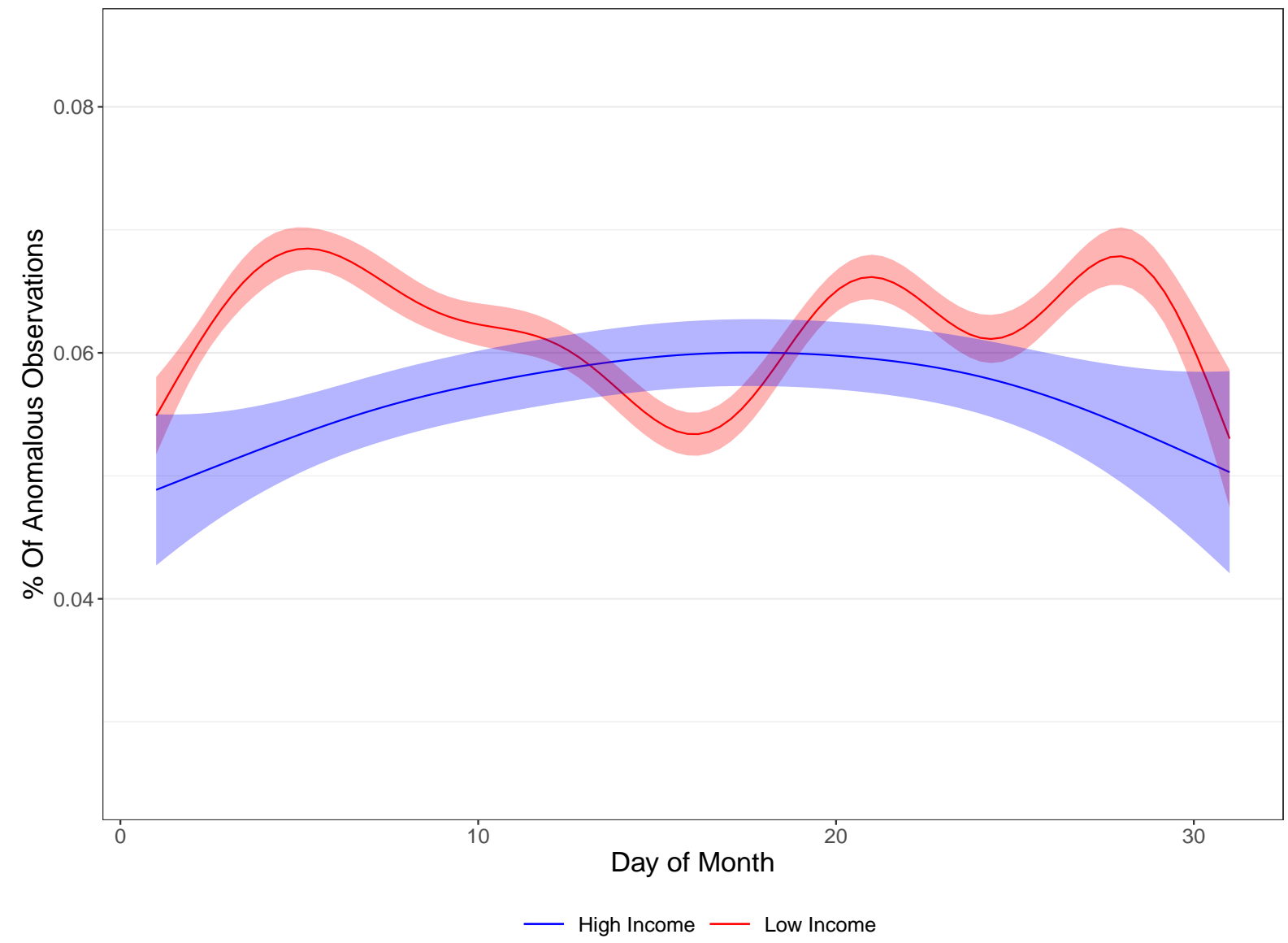

Figure S8: Differences in the proportion of anomalous negative observations between high (more than 3000 euros per month) and low-income (less than 3000 euros per month) individuals. 


\section{References Supplemental Materials}

Ayuso-Mateos, J. L., Miret, M., Caballero, F. F., Olaya, B., Haro, J. M., Kowal, P., \& Chatterji, S. (2013). Multi-country evaluation of affective experience: Validation of an abbreviated version of the day reconstruction method in seven countries. PLOS ONE, 8(4), 1-8. https://doi.org/10.1371/journal.pone.0061534

Ferguson, B. D., Tandon, A., Gakidou, E., \& Murray, C. (2003). Estimating permanent income using indicator variables.

Fisch, A. T. M., Eckley, I. A., \& Fearnhead, P. (2019). A linear time method for the detection of point and collective anomalies [arXiv: 1806.01947]. arXiv:1806.01947 [cs, stat]. http://arxiv.org/abs/1806.01947

Kahneman, D., \& Deaton, A. (2010). High income improves evaluation of life but not emotional well-being. Proceedings of the National Academy of Sciences, 107(38), 1648916493. https://doi.org/10.1073/pnas.1011492107

Kowal, P., Chatterji, S., Naidoo, N., Biritwum, R., Fan, W., Lopez Ridaura, R., Maximova, T., Arokiasamy, P., Phaswana-Mafuya, N., Williams, S., Snodgrass, J. J., Minicuci, N., D’Este, C., Peltzer, K., Boerma, J. T., \& the SAGE Collaborators. (2012). Data Resource Profile: The World Health Organization Study on global AGEing and adult health (SAGE). International Journal of Epidemiology, 41(6), 1639-1649. https:// doi.org/10.1093/ije/dys210

Simonsohn, U. (2018). Two lines: A valid alternative to the invalid testing of u-shaped relationships with quadratic regressions. Advances in Methods and Practices in Psychological Science, 1(4), 538-555. https://doi.org/10.1177/2515245918805755 
Simonsohn, U., Simmons, J. P., \& Nelson, L. D. (2020). Specification curve analysis. Nature Human Behaviour, 4(11), 1208-1214. https://doi.org/10.1038/s41562-020-0912-z

Taquet, M., Quoidbach, J., Gross, J. J., Saunders, K. E. A., \& Goodwin, G. M. (2020). Mood Homeostasis, Low Mood, and History of Depression in 2 Large Population Samples. JAMA Psychiatry, 77(9), 944-951. https://doi.org/10.1001/jamapsychiatry.2020. 0588 